\title{
The ion-aerosol interactions from the ion mobility and aerosol particle size distribution measurements on January 17 and February 18, 2005 at Maitri, Antarctica - A case study
}

\author{
Devendraa Siingh ${ }^{1, *}$, Vimlesh Pant ${ }^{1,2}$ and A K Kamra ${ }^{1}$ \\ ${ }^{1}$ Indian Institute of Tropical Meteorology, Dr Homi Bhabha Road, Pashan, \\ Pune 411 008, India. \\ ${ }^{2}$ Present address: Indian National Centre for Ocean Information Services, \\ Hyderabad 500 055, India. \\ *e-mail: devendraasiingh@tropmet.res.in devendraasiingh@gmail.com
}

A case study for the ion-aerosol interactions is presented from the simultaneous measurements of mobility spectra of atmospheric ions in the mobility range of 2.29 to $2.98 \times 10^{-4} \mathrm{~cm}^{2} \mathrm{~V}^{-1} \mathrm{~s}^{-1}$ (diameter range 0.41-109 nm) and of size distribution of atmospheric aerosol particles in the size ranges of 4.4-700 nm and 500-20,000 nm diameters made at Maitri $\left(70^{\circ} 45^{\prime} 52^{\prime \prime} \mathrm{S}, 11^{\circ} 44^{\prime} 2.7^{\prime \prime} \mathrm{E} ; 130 \mathrm{~m}\right.$ above mean sea level), Antarctica, on two days January 17 and February 18, 2005, with contrasting meteorological conditions. In contrast to January 17, on February 18, winds were stronger from the morning to noon and lower from the noon to evening, atmospheric pressure was lower, cloudiness was more, the land surface remained snow-covered after a blizzard on February 16 and 17 and the airmass over Maitri, descended from an altitude of $\sim 3 \mathrm{~km}$ after an excursion over ocean. On these days mobility spectra showed two modes, corresponding to intermediate ions and light large ions and an indication of additional one/two maxima for small/cluster ions and heavy large ions. The small ions generated by cosmic rays, and the nucleation mode particles generated probably by photochemical reactions grew in size by condensation of volatile trace gases on them and produced the cluster and intermediate ion modes and the Aitken particle mode in ion/particle spectra. Particles in the size range of 9-26 nm have been estimated to grow at the rate of $1.9 \mathrm{~nm} \mathrm{~h}^{-1}$ on February 18, 2005. Both, ions and aerosol particles show bimodal size distributions in the 16-107 nm size range, and comparison of the two size distributions suggests the formation of multiple charged ions. Attachment of small ions to particles in this bimodal distribution of Aitken particles together with the formation of multiple charged ions are proposed to result in the light and heavy large ion modes. Growth of the nucleation mode particles on February 18, 2005 is associated with the passage of the airmass over ocean. In contrast, though the ion size distributions were not much different, the aerosol size distributions did not show a dominant peak for the formation and growth of nucleation mode particles on January 17. More measurements are needed before the conclusion of this case study is generalized.

Keywords. Mobility spectra of ions; aerosol particle size distribution; Gerdian Ion Counter Battery; ion-aerosol interactions; new-particle formation at Antarctica. 


\section{Introduction}

Different electrical mobility categories in an ion mobility spectrum are inversely related to ionic mass and radius (Tammet 1995). So, a knowledge of ion mobility spectrum provides useful information to understand the interactions of ions and aerosols in the Earth's atmosphere (Misaki et al 1972; Hoppel 1977; Dhanorkar and Kamra 1991; Horrak et al 2003; Siingh et al 2005a), in characterizing the freshly nucleated charged particles with diameters less than $3 \mathrm{~nm}$ (Horrak et al 1998; Kulmala et al 2004, 2007; Hirsikko et al 2007; Gagne et al 2008; $\mathrm{Yu}$ 2010), in linking the electrical parameters to chemical properties of the atmosphere (Nagato and Ogawa 1998), and in understanding the interactions between the air and snow (Siingh et al 2007a). Consequently, the characteristic features of the electrically charged atmospheric aerosol particles and of the global electric circuit are emerging as increasingly important areas in assessing the direct and indirect aerosol climate forcing for understanding climate system (e.g., Rycroft et al 2000; Tinsley 2000, 2008; Singh et al 2004, 2011; Siingh et al 2005b, 2007b, 2008, 2011; Kirkby 2007; Williams 2009; Siingh and Singh 2010).

Earlier measurements of the ion mobility spectra were limited to small mobility ranges and generally extended over a period of only a few days (Misaki 1961, 1964; Misaki et al 1972; Kojima 1984; Dhanorkar and Kamra 1991, 1993). However, Horrak et al (2000, 2003, 2008) reported a comprehensive study, based on continuous monitoring of mobility spectra of atmospheric ions in the mobility range 0.00041 to $3.2 \mathrm{~cm}^{2} \mathrm{~V}^{-1} \mathrm{~s}^{-1}$ (diameter range $0.36-79 \mathrm{~nm}$ ), for several years, at Tahkuse Observatory in Estonia. From their data, they concluded that atmospheric ions can be classified in five categories, namely, small cluster ions (1.3$3.2 \mathrm{~cm}^{2} \mathrm{~V}^{-1} \mathrm{~s}^{-1}, 0.36-0.85 \mathrm{~nm}$ diameter), big cluster ions $\left(0.5-1.3 \mathrm{~cm}^{2} \mathrm{~V}^{-1} \mathrm{~s}^{-1}, 0.85-1.60 \mathrm{~nm}\right)$, intermediate ions $\left(0.034-0.5 \mathrm{~cm}^{2} \mathrm{~V}^{-1} \mathrm{~s}^{-1}, 1.60-7.4 \mathrm{~nm}\right)$, light large ions $\left(0.0042-0.034 \quad \mathrm{~cm}^{2} \quad \mathrm{~V}^{-1} \mathrm{~s}^{-1}\right.$, $7.4-22 \mathrm{~nm})$ and heavy large ions (0.00087$\left.0.0042 \mathrm{~cm}^{2} \mathrm{~V}^{-1} \mathrm{~s}^{-1}, 22-79 \mathrm{~nm}\right)$.

The ion mobility spectra have often been used to estimate particle size distributions (Misaki 1964; Dhanorkar and Kamra 1993; Horrak et al 1998). There is no general law relating mobility of an ion to its size for the entire range of charged particles. Relation for the mobility to particle size conversions depend upon the particles size range, i.e., whether the particles are smaller or larger than the mean free path of air molecules, and whether the particles are considered as neutral, single or multiple charged particles. The methods used by different investigators to convert mobility to particle size are described by Bricard (1949, 1962); Israel
(1970); Hoppel (1977) and Tammet (1992). In our study, we use the tabulated values of Horrak et al (2000, 2003) for the mobility-to-size conversion of ions. Detailed method for this conversion is described by Tammet (1995). Virkkula et al (2007) converted his ion mobility spectra measured from December 14, 2004 to January 30, 2005 at Aboa, Antarctica, to the particle size distributions in the range of $0.34-40 \mathrm{~nm}$ diameter and computed the median diameter growth rates of negatively charged particles in size classes $1.3-3,3-7$ and $7-20 \mathrm{~nm}$ as equal to $1.1,1.5$ and $4.3 \mathrm{~nm} \mathrm{~h}^{-1}$, respectively, and a little smaller for positively charged particles. Recent ion mobility measurements identify the formation of intermediate ions at various locations such as in boreal forest in southern Finland and Tahkuse Observatory, Estonia (Hirsikko et al 2007; Komsaare et al 2007), in the marine coastal environment of Mace Head (Vana et al 2008), in the Baltic Sea region (Komppula et al 2007) and along the trans-Siberian railroad from Moscow to Vlavivostok (Vartiainen et al 2007).

Atmospheric ions and aerosols over a coastal region are mostly comprised of those generated by the local sources, transported with the winds from the ocean and continent, and transported down under subsidence from the free atmosphere. Identification of the sources of these ions and aerosols is further complicated by the anthropogenic pollutants carried from the continent. However, if the measurement site is located at a remote place, such as in Antarctica, the effects of anthropogenic pollutants can be neglected and the characterization, sources, dynamics and interaction of ions and aerosols can be studied in a clean environment. In this paper, we report a case study of ion-aerosol interactions from our measurements of ion mobility spectra made at Maitri $\left(70^{\circ} 45^{\prime} 52^{\prime \prime} \mathrm{S}, 11^{\circ} 44^{\prime} 2.7^{\prime \prime} \mathrm{E}\right.$; $130 \mathrm{~m}$ above mean sea level), Antarctica on two days (January 17 and February 18, 2005) during the 24th Indian Scientific Expedition to Antarctica in January-February, 2005. Simultaneous measurements of the aerosol size distributions in the submicrometer and micrometer ranges have been made and compared with the ion size distributions computed from the mobility spectra. Comparison of our ion and aerosol size distributions is used to bring out the advantage of using the Gerdien ion counter for the aerosol size measurements with the differential measuring technique.

\section{Instrumentation}

Based on Blackwood's (1920) concept of double electrode condenser method for the better resolution of the mobility spectrum, Whipple (1960) 
introduced a new method in which the values of current obtained on the second electrode of a double-electrode condenser when either potential or airflow or both are varied, may be reduced to a single characteristic curve, which is a plot of current-voltage ratio against air flow-voltage ratio. Dhanorkar and Kamra (1991) have extended Whipple's method to obtain a single characteristic curve by varying voltage of the inner electrode while maintaining constant airflow, during the observation period.

The critical mobility of the first and the second electrodes are $k_{1}=U / 4 \pi C_{1} V$ and $k_{2}=U /$ $4 \pi\left(C_{1}+C_{2}\right) V$, respectively, where $U$ is the volume rate of airflow, $C_{1}$ and $C_{2}$ are the effective capacitance of the first and the second electrodes and $V$ is the applied voltage. The current to the second electrode, $I_{2}$, is written as (Whipple 1960; Misaki 1961):

$$
\begin{gathered}
\frac{I_{2}}{V}=4 \pi e\left[C_{1} k_{1} \int_{k_{2}}^{k_{1}} f(k) d k+\left(C_{1}+C_{2}\right) \int_{0}^{k_{2}} k f(k) d k\right. \\
\left.-C_{1} \int_{0}^{k_{1}} k f(k) d k\right]
\end{gathered}
$$

where $e$ is electronic charge and $f(k)$ is mobility distribution function. The first derivative of the above equation gives the number of ions $/ \mathrm{cm}^{3}$ between the mobility values $k_{2}$ and $k_{1}$, and resolution is determined by the ratio $k_{2} / k_{1}=C_{1} /\left(C_{1}+\right.$ $C_{2}$ ) (Whipple 1960).
An ion counter consisting of three Gerdien condensers called as the Gerdien Ion Counter Battery (GICB), which was being used for measurements of ion concentration at Maitri during the 24th Indian Scientific Expedition to Antarctica, was used in the mobility-measuring mode for measurement of ion mobility spectra on two days. The electrode of each condenser consists of two coaxial electrodes of equal diameters but insulated from each other. Table 1 shows the dimensions of each condenser. All the three condensers are fixed on an end-plate of a cylinder. A fan, fixed on the other end of cylinder, sucks the air through all the three condensers. Details of the instrument are described by Siingh et al (2005a, 2007a).

Non-magnetic stainless steel was used for fabrication of GICB to meet the requirements of Antarctic environment. All electronic components in the electronic circuitry were of military grade to withstand the subfreezing temperatures of up to $-40^{\circ} \mathrm{C}$. Inputs from all the three condensers were amplified with separate amplifiers placed close to the sensor and fed through Teflon insulated coaxial cables, to a data logger placed in a nearby Kamet Observatory of $2 \times 1.5 \times 1.5 \mathrm{~m}$ dimensions.

In our measurements, the flow rate is kept fixed and potential of each electrode is varied independently by three different power supplies. Values of the flow rate, applied potential and critical mobility of each condenser are given in table 2. After changing the potential in condensers, the averaged values of current in the small-, intermediate- and large-ion condensers are manually noted after a time period of 5 minutes to avoid any displacement current. Maintenance of zero in each condenser's

Table 1. Dimensions and other technical parameters of three condensers of Gerdien Ion Counter Battery (GICB).

\begin{tabular}{lccc}
\hline Dimensions/constants & $\begin{array}{c}\text { Small-ion } \\
\text { condenser }\end{array}$ & $\begin{array}{c}\text { Intermediate-ion } \\
\text { condenser }\end{array}$ & $\begin{array}{c}\text { Large-ion } \\
\text { condenser }\end{array}$ \\
\hline Length of the outer electrode $(\mathrm{cm})$ & 40 & 80 & 120 \\
Length of the first inner electrode $(\mathrm{cm})$ & 15 & 40 & 80 \\
Length of the second inner electrode $(\mathrm{cm})$ & 5 & 10 & 20 \\
Diameter of the outer electrode $(\mathrm{cm})$ & 98 & 60 & 38 \\
Diameter of the inner electrodes $(\mathrm{cm})$ & 76 & 37 & 22 \\
Flow rate $(\mathrm{l} / \mathrm{s})$ & 8.6 & 1.8 & 0.29 \\
\hline
\end{tabular}

Table 2. Applied potential and critical mobility of the second condenser.

\begin{tabular}{llcc}
\hline Dimensions/constants & \multicolumn{1}{c}{ Small-ion condenser } & Intermediate-ion condenser & Large-ion condenser \\
\hline Potential applied in Volts & $2,4,8,16,26,36$ & $40,80,120,160,200,300$ & $25,50,200,400,600,800,1000$ \\
Critical mobility & $2.29,1.1482,0.5741$, & $0.1164, .05822,0.03181$, & $0.01188,0.005836,0.001459$, \\
in $\mathrm{cm}^{2} \mathrm{~V}^{-1} \mathrm{~s}^{-1}$ & $0.2870,0.1913,0.12757$ & $0.0291,0.02328,0.01552$ & $0.0007295,0.0004863$, \\
& & & $0.00036475,0.000298$ \\
\hline
\end{tabular}


output was repeatedly checked, both in laboratory and in field, by stopping the airflow through the condenser. Observations for one spectrum were completed within an hour.

In a normal streamline air-flow in each Gerdiens condenser of GICB, the collection of charged particles depends upon the air speed and the electric field applied perpendicular to the air-flow between the inner and outer electrodes of the condenser. However, when the instrument is placed in the atmosphere, strong winds can change the suction rate and generate turbulence in the air-flow inside the condenser. This can modify the collection efficiency of charged particles on the electrodes. Therefore, GICB was placed with its condensers perpendicular to the prevailing wind direction, to minimize the effect of strong winds on the suction rate in condensers. GICB was placed near the ground with its inlets at $60 \mathrm{~cm}$ above the ground. At this randomly selected moderate height, the effects due to distortion of airflow due to proximity of surface layer, non-equalization of inlet potential, and electrode effect, are minimized.

Measurements of aerosol number size distribution were made in the size range of 4.4-700 nm diameter with Scanning Mobility Particle Sizer (SMPS, TSI model 3936) and in the size range of 500-20,000 nm diameter with an Aerodynamic Particle Sizer (APS, TSI model 3321) at the ambient values of relative humidity. It needs to be mentioned that the SMPS also measures mobility spectra of aerosol particles and converts it to the particle sizes. In our measurements, we have used the procedure of Tammet (1995) (table 2 in Horrak et al 2003) for the mobility-to-diameter conversion. All the aerodynamic diameters measured with the APS system have been converted to electrical mobility diameters following the procedure of Peters et al (1993). In doing so, the ratio of slip correction factors has been assumed as 1 and particles are assumed as spherical (Khlystov et al 2004; Ondracek et al 2009). Further, since the particle density is assumed as $1800 \mathrm{~kg} \mathrm{~m}^{-3}$ in dry atmosphere of South Pole (Park et al 2004) and as $1200 \mathrm{~kg} \mathrm{~m}^{-3}$ in high humidity environment over the mid-latitude regions of southern Indian Ocean (Pant et al 2008, 2011), a value of $1600 \mathrm{~kg} \mathrm{~m}^{-3}$ is assumed for particle density at the coastline Maitri station where the atmospheric temperatures fluctuate around freezing point during the months of January and February and both solid and liquid particles coexist. However, since the aerodynamic and Stoke's diameters are related through square root of the particle density, changes in the assumed value of density would manifest as a change in the particle diameter. So, in absence of any data on the extents of solid and liquid phase particles over Maitri, this assumption may contribute to some uncertainty in the calculated diameters of the particles measured by APS system. However, considering the extreme cases of all-solid or all-liquid particles, our estimates of the APS measured particle diameters will not differ by more than $15 \%$ due to this assumption. The APS and SMPS systems have a resolution of up to 64 and 32 channels per decade, respectively, and a measurement cycle of 10 minutes for the whole size range. Both instruments were kept inside Kamet Observatory and the air samples for the APS and SMPS systems were drawn at the rates of $5 \mathrm{lpm}$ (liter per minute) (sample and sheath flow rates were kept at $1 \mathrm{lpm}$ and $4 \mathrm{lpm}$, respectively) and $3.3 \mathrm{lpm}$ (sample and sheath flow rates were kept at $0.3 \mathrm{lpm}$ and $3.0 \mathrm{lpm}$, respectively), respectively, through two conductive silicon tubes each of $0.5 \mathrm{~cm}$ internal diameter and $1.0 \mathrm{~m}$ and $0.5 \mathrm{~m}$ length, respectively. The inlets of tube were cleaned daily with butanol because of its cleansing properties and allowed to dry. Measurements of meteorological parameters were made with a weather-station with its sensors mounted at $10 \mathrm{~m}$ height. Cloud coverage was estimated at every one hour.

\section{Measurement site}

Measurements were made at the Indian station Maitri, located in Schirmacher Oasis in Dronning Maud Land (also known as Queen Maud Land), East Antarctica. Maitri has steep cliffs and an iceshelf on the northern side and polar ice on the southern side. The generators, gas plant, incinerator and living modules are about $300 \mathrm{~m}$ away in the southwest direction from the instruments. Any pollutants released from them had very little chance of reaching the site of measurements due to the prevailing southeasterly winds which were $>3 \mathrm{~m} \mathrm{~s}^{-1}$ for most of the time. The site is dominantly covered by sandy and loamy type of soil. Other features of the site are described in detail by Siingh et al (2007a).

\section{Observations}

Measurements of mobility spectra of positive and negative ions in the range of 2.29 to $2.98 \times$ $10^{-4} \mathrm{~cm}^{2} \mathrm{~V}^{-1} \mathrm{~s}^{-1}$ (diameter range $0.41-109 \mathrm{~nm}$ ) were made at Maitri during different periods from January 17 to February 18, 2005. Simultaneous measurements of size distributions of aerosol particles were made in the size ranges of $16-700 \mathrm{~nm}$ on January 17, 4.4-160/10-400 nm on February 18, and 500-20,000 $\mathrm{nm}$ diameters on both days. These 


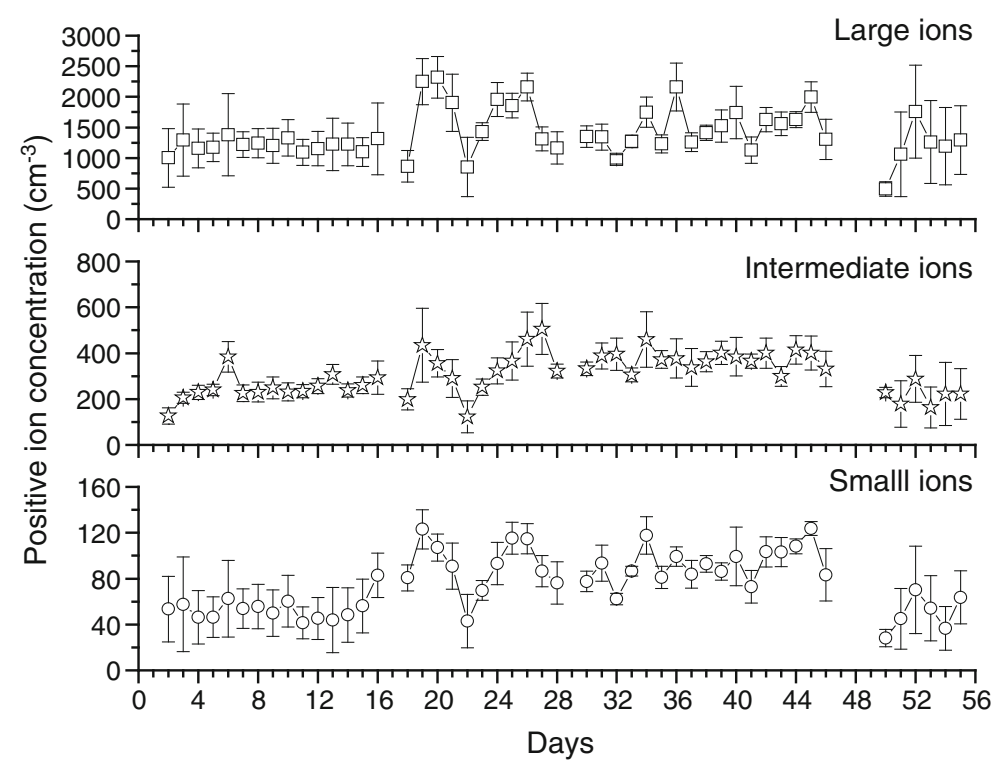

Figure 1. Daily average values of the small-, intermediate-, and large-positive ion concentrations for the period of January 2 to February 24, 2005.

Table 3. The ion mobility and particle size ranges of different types of ions.

\begin{tabular}{lcccc}
\hline & Small/cluster ions & Intermediate ions & Light large ions & Heavy large ions \\
\hline Mobility range $\left(\mathrm{cm}^{2} \mathrm{~V}^{-1} \mathrm{~s}^{-1}\right)$ & $2.29-0.42$ & $0.42-0.0329$ & $0.0329-0.0012$ & $0.0012-0.000298$ \\
Diameter range $(\mathrm{nm})^{\mathrm{a}}$ & $0.41-1.78$ & $1.78-8.0$ & $8.0-50$ & $50-109$ \\
\hline
\end{tabular}

${ }^{\mathrm{a}}$ Estimates of equivalent diameter of particles have been calculated assuming single charged particles

two days were selected for a special campaign of operating the ion counter in the mobilitymeasuring mode. The meteorological conditions prevailing on these two days are described in section 4.1. Diurnal ranges of atmospheric temperature on both days were typical of those prevailing in this season. On February 18, 2005, winds were stronger from the morning till noon and lower from the noon till evening; atmospheric pressures were lower and cloudiness was more than that of a typical day in this season. Because of difficulties in operating manually the instrument in this mode in harsh environment of Antarctica, and to fulfill our main objective of getting a continuous time series of ion concentration (reported in Siingh et al 2007a) with least interruptions, such measurements were made only on two days. Measurements of ion concentrations over the whole period of our stay at Antarctica, are described by Siingh et al (2007a) and are shown in figure 1. Diurnal variations in the small and large positive ion concentrations, though not systematic, were almost similar to each other. On the other hand, variations in the intermediate ion concentrations were independent of variations in the small/large positive ions and exhibited a diurnal variation which was similar to that of atmospheric temperature on fair weather days with a maximum during the day and minimum during the night hours. No such diurnal variation in intermediate positive ion concentration was observed on cloudy days when variations in them were also similar to those in the small/large positive ion concentrations. Magnitude of diurnal variation in intermediate positive ion concentration on fair weather days increased with the lowering of atmospheric temperature in this season. Variations in intermediate positive ion concentration are explained on the basis of the formation of new particle by the photolytic nucleation process. Unfortunately, because of an error in our earlier computations, absolute values of the small-, intermediate-, and large-positive ion concentrations were overestimated by constant factors of 4.5, 5.8, and 5.9, respectively, and wrongly reported in Siingh et al (2007a). This error, however, does not invalidate the conclusions of the paper. As discussed in section 4.1, meteorological conditions and airmass characteristics over Maitri on January 17 and February 18, 2005 were much different from each other. The results obtained and the meteorological conditions prevailing on these two days are described below. Ranges of ion mobility and particle sizes for different types of ions are given in table 3 . 


\subsection{Meteorological aspects}

On January 17 and February 18, Maitri experienced, respectively, 22 and 18 hours of sunshine the Sun being at lower horizons during the morning and evening hours (the low Sun periods) and at higher horizons during the noon hours (the high Sun periods). Figure 2 shows the variations of various meteorological parameters recorded at Maitri on Janaury 17 and February 18, 2005. Weather remained cloudy for the whole day on January 17, 2005 and the atmospheric temperature varied from $-2.2^{\circ}$ to $1.8^{\circ} \mathrm{C}$. Southeasterly winds of $2-6 \mathrm{~m} \mathrm{~s}^{-1}$ prevailed for the whole day. Atmospheric pressure did not show much variation.

On the contrary, weather was highly variable on February 18, 2005, with thick clouds and light fog. As a result of a blizzard occurring on February 16 and 17, the land at Maitri station was almost totally covered with snow on February 18, 2005 and the atmospheric temperature varied from $-2.2^{\circ}$ to $2.4^{\circ} \mathrm{C}$. Strong southeasterly winds of up to $\sim 12 \mathrm{~m} \mathrm{~s}^{-1}$ that prevailed in the early morning hours, weakened in the afternoon and calm conditions prevailed from 1700 UT to 2100 UT (LT is ahead of UT by $\sim 45 \mathrm{~min}$ ) when winds again picked up a little. The atmospheric pressure slowly, but steadily, increased from $\sim 950 \mathrm{hPa}$ at $0600 \mathrm{UT}$ to $958 \mathrm{hPa}$ at $2300 \mathrm{UT}$.

An examination of the 5-day backward trajectories, drawn for $500 \mathrm{~m}$ altitude (above ground level) in figure 3 reveals that the airmass over Maitri at 0200 UT on January 17 was of continental origin and descended from a height of 1000 to $2000 \mathrm{~m}$ along the coastline from the eastern Antarctica. However, at 0800, 1400 and 1900 UT, the airmass originated over ocean and descended from a height of 1500 to $2500 \mathrm{~m}$ along the coastline of eastern Antarctica. On February 18, 2005, although the origin of airmass over Maitri was continental before $1500 \mathrm{UT}$, it shifted to coastline at 1600 UT. In a significant difference from
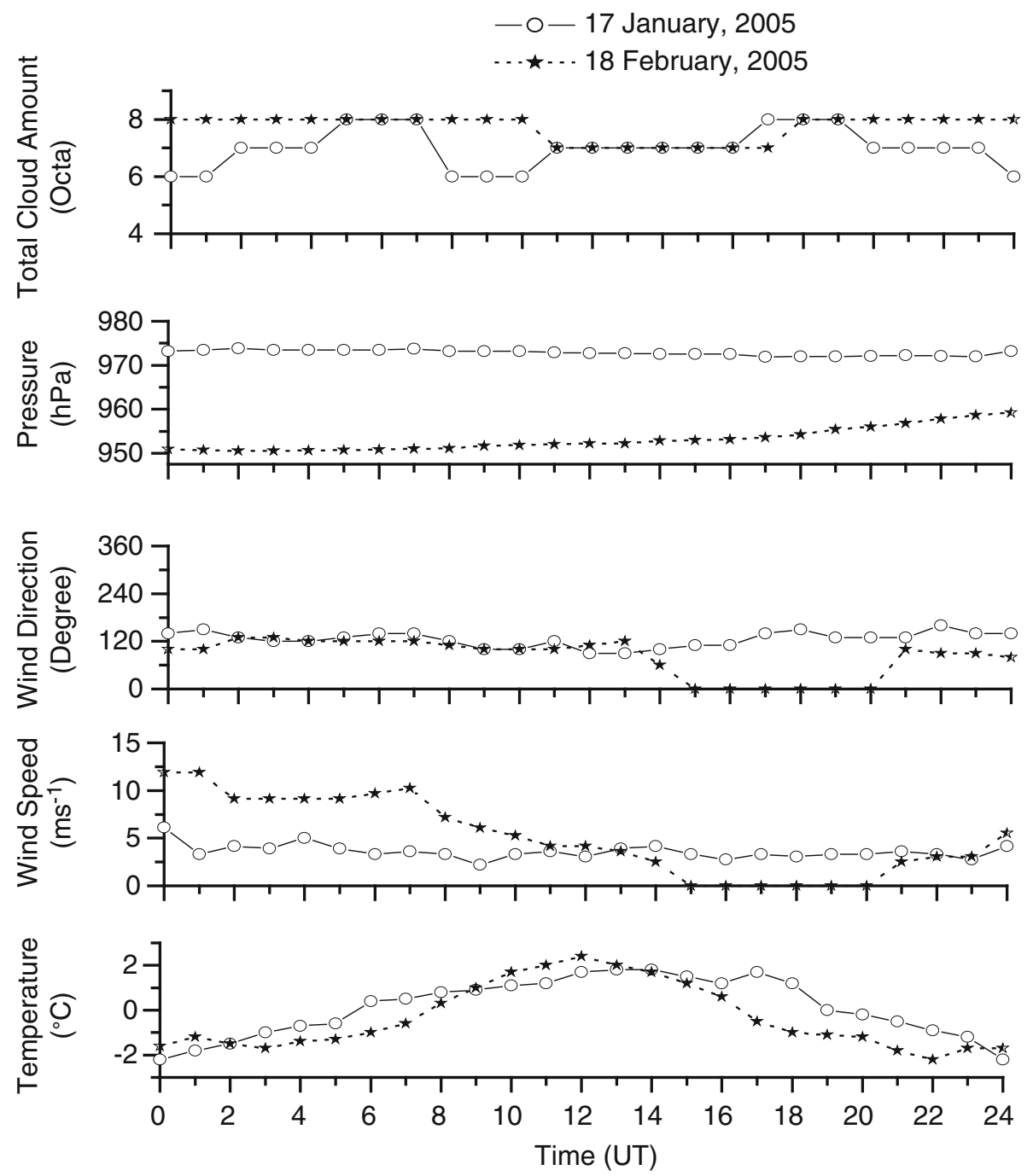

Figure 2. Variations of various meteorological parameters recorded at Maitri on January 17 and February $18,2005$. 
(a)
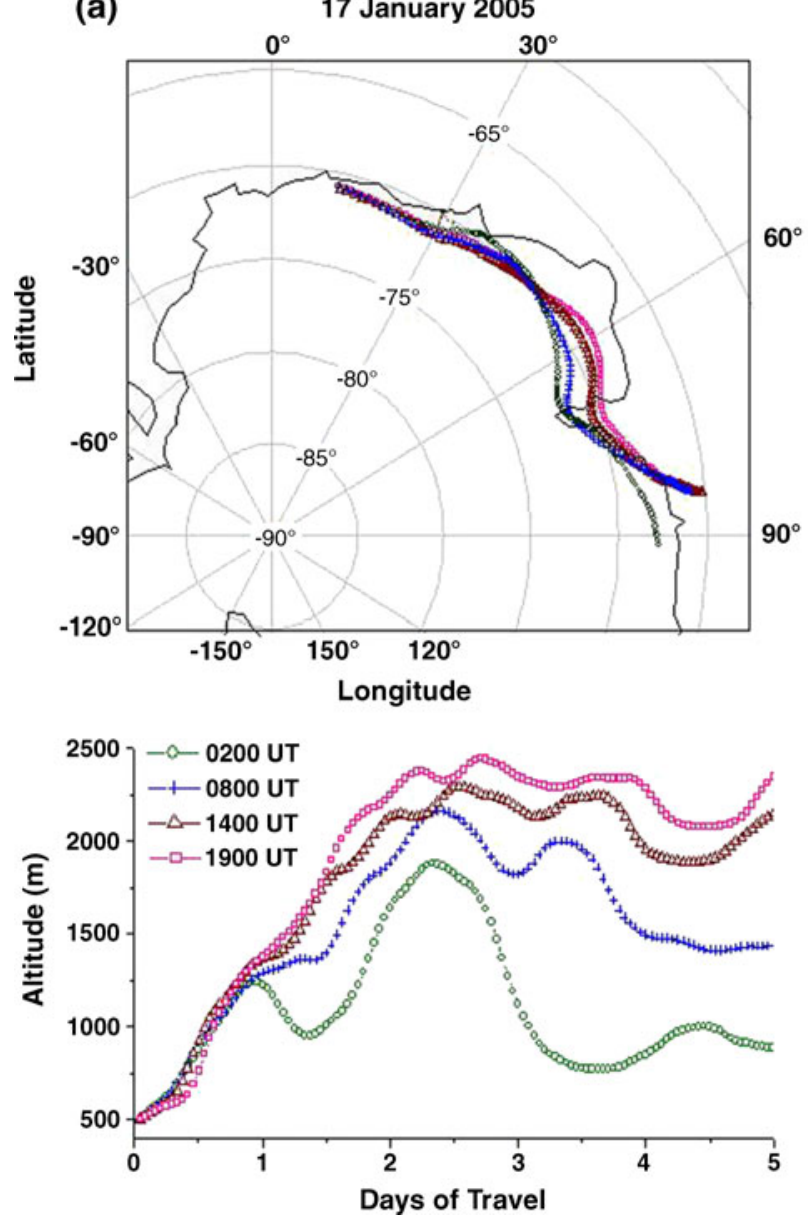

(b)

18 February 2005
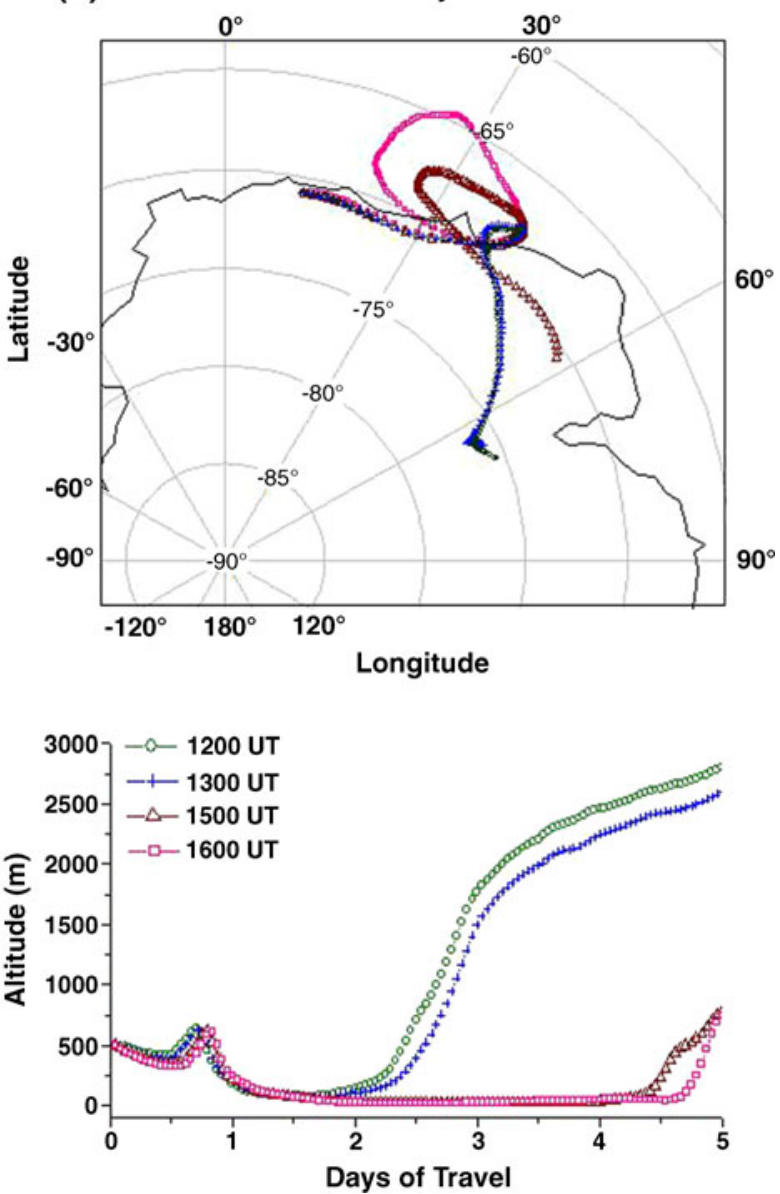

Figure 3. The 5-day back-trajectories of the airmass arriving at $500 \mathrm{~m}$ at Maitri at different times on (a) January 17,2005 and (b) February 18, 2005. Back trajectories are drawn using NOAA HYSPLIT Model (Draxler and Rolph 2003).

the case of January 17, the airmass on February 18 crossed over to the ocean, completed a circle and then approached back to Maitri from the eastern side along the coastline. At 1200 UT and 1300 UT the airmass descended from $\sim 3 \mathrm{~km}$ altitude. Examination of the surface wind flow patterns and of contour plots of vertical velocity at different pressure levels (http://www.cdc.noaa.gov) also supported that airmass over Maitri was transported from lower latitudes and it descended from higher southern latitudes on February 18, 2005.

\subsection{Ion-mobility distribution}

The mobility distributions of positive and negative ions, measured with a time-gap of $30 \mathrm{~min}$ between them, at different times on January 17 and February 18, 2005, are shown in figures 4 and 5 , respectively. Time periods of making measurements of a mobility spectrum and total number of ions of positive or negative polarity, $\mathrm{N}_{+}$or $\mathrm{N}_{-}$, during that period are also shown in each panel. Total number concentrations of ions are 3-7 times lower than those observed at a tropical land station (Dhanorkar and Kamra 1991). However, these concentrations are roughly of the same order of magnitude as at the mid-latitude station (Horrak et al 2003). Table 4 also shows the ratio of $\mathrm{N}_{+} / \mathrm{N}_{-}$, during different periods assuming that total number of ions of each polarity remained constant during the measuring period, after an interval of half an hour. These observations did not show any strong manifestation of electrode effect during these periods.

The smoothed curves for the three adjacent points averaging the value of size distribution derived from each histogram are also drawn in figures 4 and 5. All mobility distribution curves, show at least two maxima, each one corresponding to intermediate ion and light large ion modes as per the categorization of Horrak et al (2003). In addition, the smoothed curves, in most of the panels, show a change in tendency from the decreasing to increasing values of fraction concentrations just prior to reaching the lower and upper limits of 


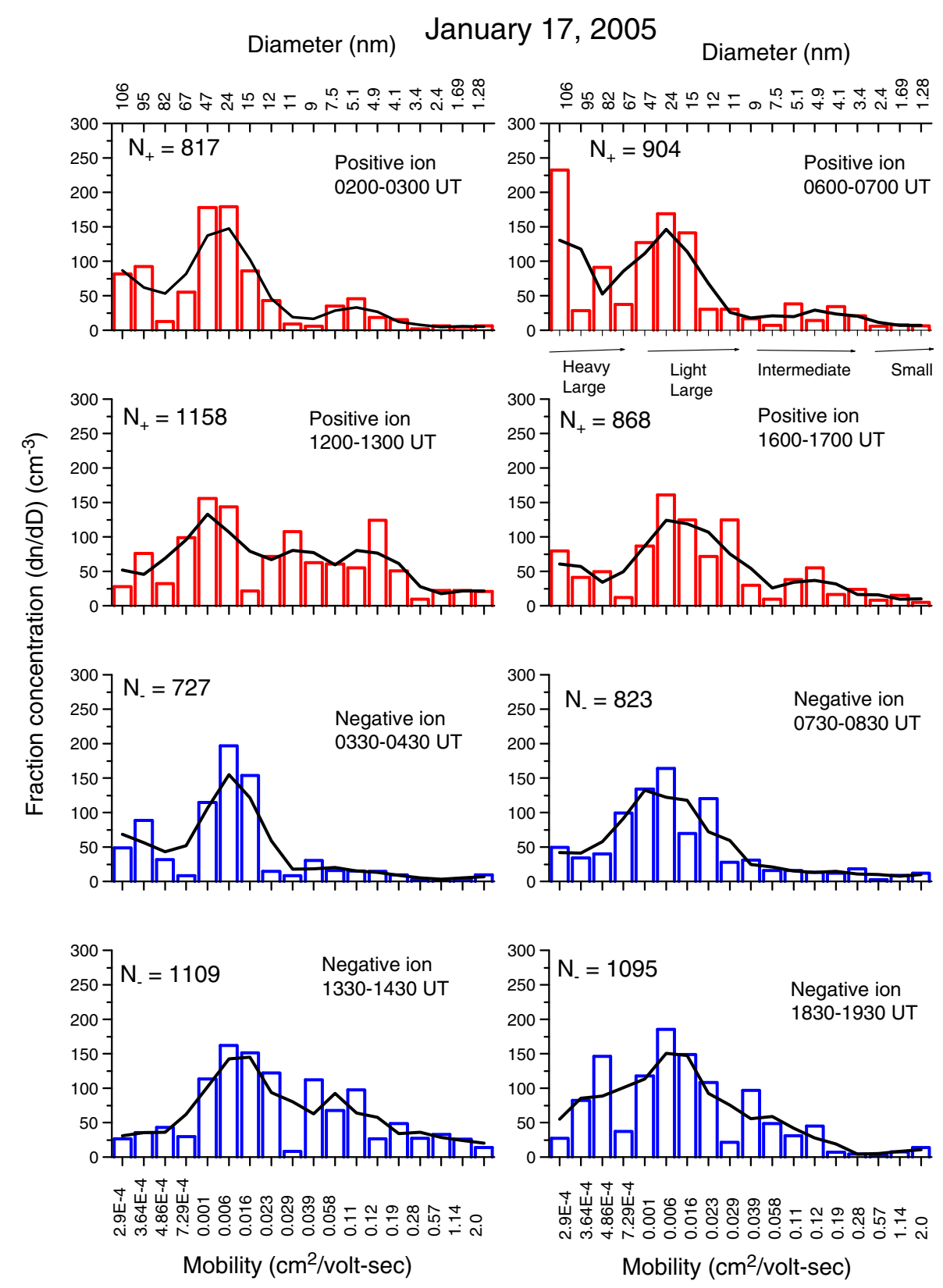

Figure 4. Mobility spectra of positive and negative ions observed at Maitri on January 17, 2005. Each panel also shows the time period of measurement and total numbers of positive and negative ions $\left(\mathrm{N}_{+}\right.$and $\left.\mathrm{N}_{-}\right)$during the period. The smoothening curve in each panel is drawn for the 3-point adjacent averaging of size distribution derived by histogram.

the mobility spectra. The mobility values at the extreme ends of the mobility spectra fall in the mobility ranges of heavy large and small/cluster ions. These reversals in the tendency of the curves suggest that probably the modes for the heavy and small/cluster ion categories may lie at or beyond these extreme values of mobility. Such an inference is supported by the presence of some higher bars relative to adjacent bars in heavy large and small/cluster ion mobility ranges in the histograms of figures 4 and 5 . The inference is also supported by the fact that the small ions generated by cosmic rays, and the large ions formed by the attachment of ions and aerosol particles, are all pervasive quantities at land and coastal sites. Figures 4 and 5, therefore, show at least two modes for the intermediate and light large ions in all panels and an indication of additional one/two maxima in the mobility ranges of small/cluster and heavy large ions in the most panels. Upper limit of mobility range of light large ions in our observations, however, extended to $0.0012 \mathrm{~cm}^{-2} \mathrm{~V}^{-1} \mathrm{~s}^{-1}(49.68 \mathrm{~nm})$ diameter. Table 5(a and b) shows the mode diameters and ion concentrations at different times on January 17 and February 18, 2005, respectively, for ions of both polarities. Tabulated values of Tammet 
February 18, 2005

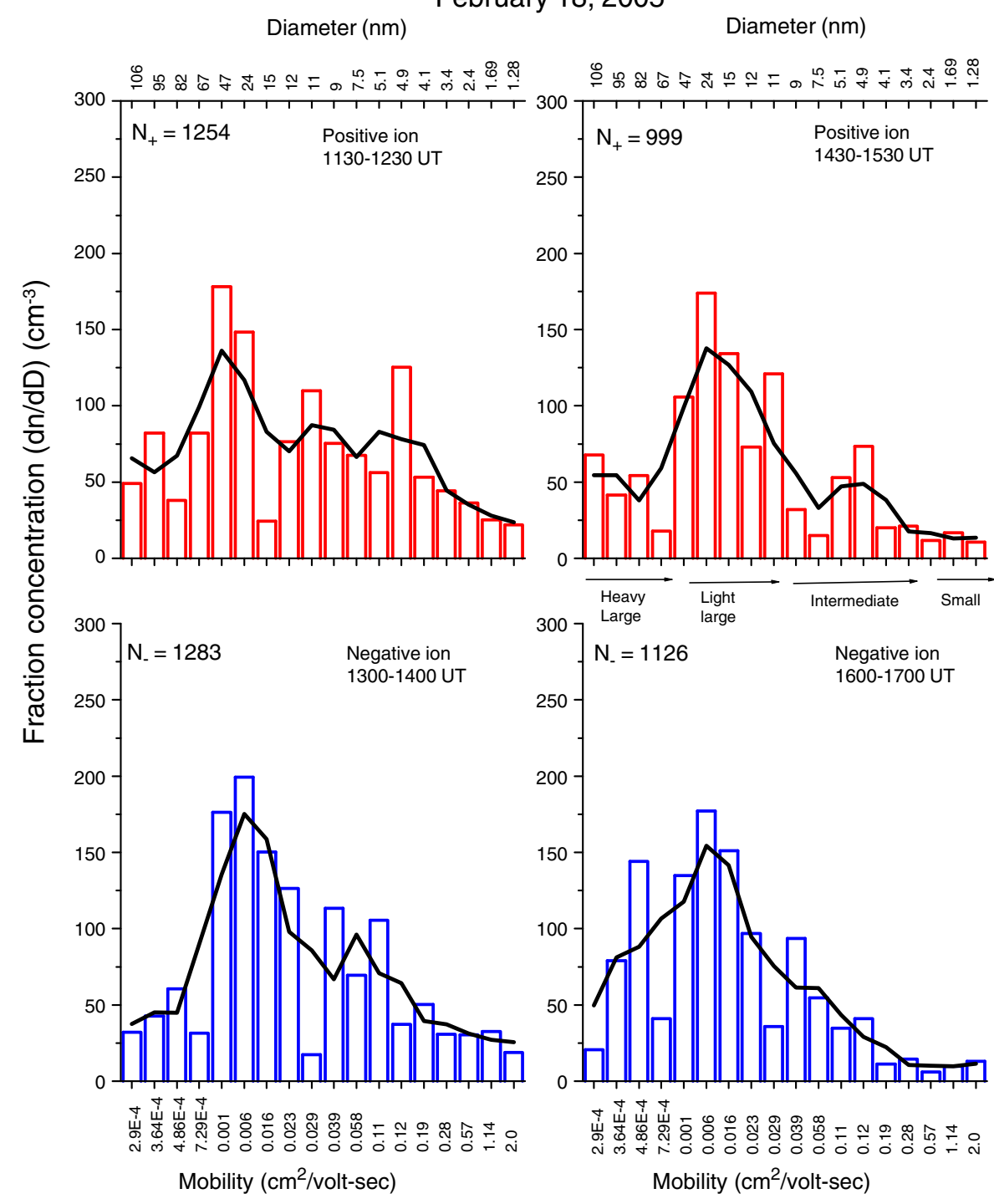

Figure 5. Mobility spectra of positive and negative ions observed at Maitri on February 18, 2005. Each panel also shows the time period of measurement and total numbers of positive and negative ions $\left(\mathrm{N}_{+}\right.$and $\left.\mathrm{N}_{-}\right)$during the period. The smoothening curves are drawn as in figure 3.

Table 4. The ratio of $N_{+} / N_{-}$during different periods.

\begin{tabular}{|c|c|c|c|c|c|c|}
\hline \multirow[b]{2}{*}{ Time (UT) } & \multicolumn{4}{|c|}{ January 17, 2005} & \multicolumn{2}{|c|}{ February 18, 2005} \\
\hline & 0200-0430 & 0600-0830 & $1200-1430$ & 1700-1930 & $1130-1400$ & $1430-1700$ \\
\hline $\mathrm{N}_{+} / \mathrm{N}_{-}$ & 1.12 & 1.09 & 1.04 & 0.79 & 0.98 & 0.89 \\
\hline
\end{tabular}

(1995) and Horrak et al (1994, 2000, 2003) were used for conversion of the mobility to the size of ions. Particles with multiple charges were not taken in to account. So, part of the high concentrations of light large ions could be (as will be inferred later in section 5) due to particles with multiple charges. Our measurements did not have sufficient resolution at the higher end of mobility, to distinguish between the small and cluster ion ranges as done by Horrak et al (2000). Hence, their properties are discussed here together in one category. Negative small ions mostly show a maximum at higher values of mobility than those for positive ions and often it exceeds $2 \mathrm{~cm}^{2} \mathrm{~V}^{-1} \mathrm{~s}^{-1}(1.28 \mathrm{~nm})$, the upper limit of our ion counter for mobility measurements, indicating presence of freshly generated high mobility small ions. Because of very small radioactive emissions from the soil at Maitri (Ramachandran and 


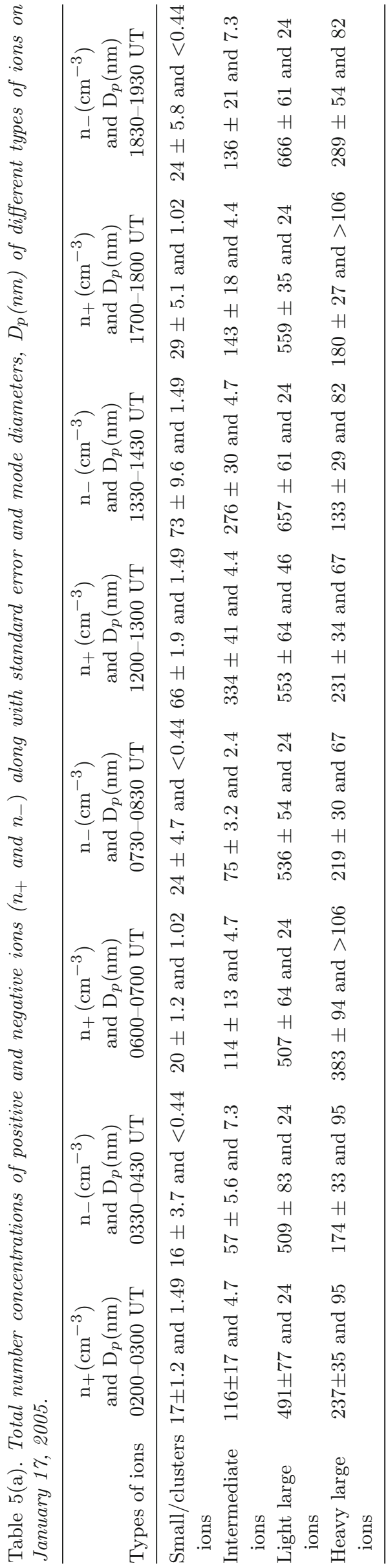

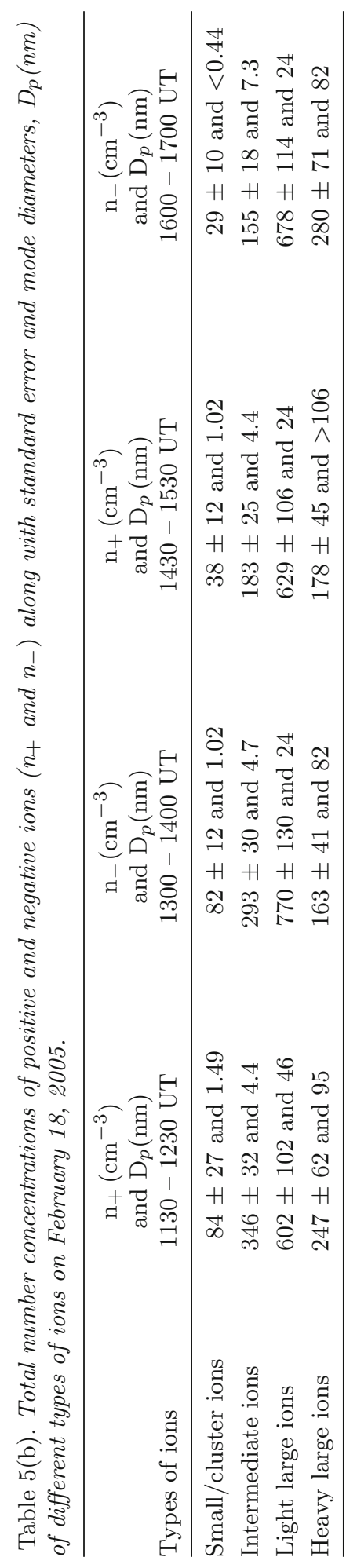


Balani 1995), most of the small ions are likely to be generated by cosmic rays. Very small concentrations of small ions during low Sun periods also indicate that any accumulation of radioactive gases emitted from the Earth's surface, is small or negligible even when the vertical stability is large during low Sun periods. The reason for not observing the maxima in our observations, in the morning hours of larger stability as observed at some continental places in the tropics or mid-latitudes, is likely to be because of similar reasons (Dhanorkar and Kamra 1991, 1993; Horrak et al 2003; Vana et al 2004).

Concentrations of both positive and negative intermediate ions in table $5(\mathrm{a}$ and $\mathrm{b}$ ) and in figures 4 and 5 were comparatively lower during low Sun periods and dramatically increased during high Sun periods. For example, total concentration of positive and negative intermediate ions is highest for the measurements made between 1130 and 1430 UT on January 17 and February 18 (table 5). This increase can be associated with the increase in the rate of production of intermediate ions by photochemical reactions with the increase in solar radiation or alternatively to some still unidentified mechanism which can produce intermediate ions during cloudy or even night-time conditions without UV under low condensation sinks (Wiedensohler et al 1997; Meters et al 2005; Lee et al 2008). On both days, while mode for positive intermediate ions appeared at 4.4$4.7 \mathrm{~nm}$ diameter, mode for negative intermediate ions shifted to larger particles of $7.3 \mathrm{~nm}$ diameter during the low Sun periods. A comparison of total concentration of intermediate ions observed at different places shows that the process responsible for the production of intermediate ions is much more active at Maitri than at the tropical station, Pune (Dhanorkar and Kamra 1991, 1993) or at the mid-latitude station, Tahkuse (Horrak et al 2003) but comparable to the coastal station at Aboa, Antarctica (Virkkula et al 2007).

The mode for light large ions had maximum ion concentrations in all mobility spectra for ions of either polarity shown in figures 4 and 5 . Unlike in the case of intermediate ions, the maxima for light large ions in these figures, always appeared and were dominant in all spectra during both, high and low Sun periods. Contrary to intermediate ions, the concentrations of light large ions of positive polarity were always lower than those of negative polarity. The mode for light large ions was normally fixed at $23.7 \mathrm{~nm}$ for ions of both polarities (figures 4 and 5). However, sometimes, as from 1200 to 1300 UT on January 17 and from 1130 to 1230 UT on February 18, 2005, evolution of intermediate ions extended this mode to larger diameters and increased the intermediate ion concentrations. At all times in these figures, however, the intermediate and light large ion modes were always distinctly separated, with a well-marked minimum between the two categories. Remarkably, while no separate mode for light large ions was observed in warm tropical climate of Pune (Dhanorkar and Kamra 1991, 1993) and it shifted its position from afternoons to late afternoons in cold climate of midlatitude at Takhuse (Horrak et al 2003), a dominant maximum for light large ions was observed at all times at Maitri.

Heavy large ions appeared at all times and their size varied over a large range of particle sizes as compared to that of light large ions. Since large ions are generally considered to be formed by the attachment of small ions to aerosol particles, the low concentrations of ions observed in this category indicate presence of low concentrations of such aerosol particles in the Antarctic environment. These particles $(52-79 \mathrm{~nm})$ are close to the critical size $(80 \mathrm{~nm})$ that can act as cloud condensation nuclei in the atmosphere (Hoppel et al 1990; Raes et al 2000).

\subsection{Aerosol particle size distribution}

Figure 6 shows the variations of aerosol size distributions in the size ranges of $500-20,000 \mathrm{~nm}$ in upper panel and 10-400 $\mathrm{nm}$ diameters in lower panel on January 17, 2005. Size distributions in both size ranges remained almost invariant with time with mode diameters appearing between 700 and $900 \mathrm{~nm}$, and 60 and $100 \mathrm{~nm}$ diameters. These mode-diameters will shift to somewhat lower values in the presence of hygroscopic particles and higher values of humidity. The APS measured mode diameters may, however, differ by as much as $15 \%$ from the calculated ones, in view of our assumption for particle density of $1600 \mathrm{~kg} \mathrm{~m}^{-3}$, as discussed in section 2. Since there was no appreciable growth of nucleation and Aitken mode particles on this day, these particles must be either aged ones or transported from some other place. The observation is supported by the backward trajectories on January 17 in figure 2, which show that the airmass over Maitri was transported from a long distance along the coastline of the Antarctic continent.

Variations in aerosol size distributions during the measurement period on February 18, 2005 (figure 7) were significantly different from those on January 17,2005 . While the two maxima appearing in the January 17 aerosol size spectra, continued to appear at approximately the same positions. The 60-100 nm high values in lower panel became somewhat weaker with the passage of time. A new peak appeared at $\sim 12 \mathrm{~nm}$ at around $1100 \mathrm{hr}$ and gradually propagated to $\sim 24 \mathrm{~nm}$ by the end of day. The growth of particles may be either by condensation 
(a)
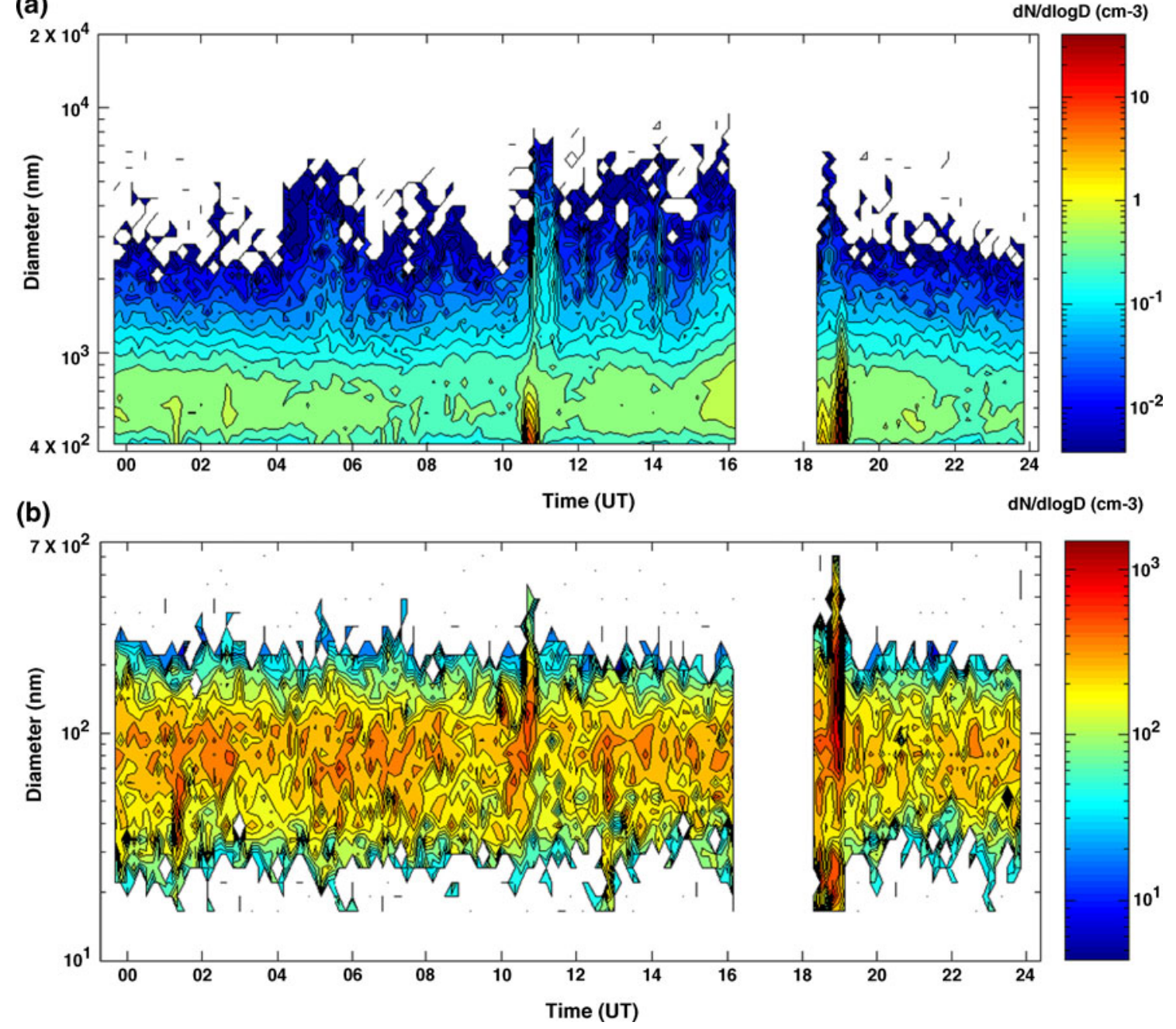

Figure 6. Time variations of the size distributions of particles in the size ranges of (a) 500-20,000 $\mathrm{nm}$ and (b) 16-700 $\mathrm{nm}$ diameter particles on January 17, 2005. Size ranges (a) and (b) exhibit a maximum each at 700-900 nm and 60-100 nm diameter, respectively.

of low volatile gases or by coagulation or both. This mode dominated the aerosol size distributions and had particle concentrations of 1-2 orders of magnitude higher than that of accumulation mode at $60-100 \mathrm{~nm}$ diameter. Moreover, the new mode was dynamic in character and slowly but steadily shifted from $12 \mathrm{~nm}$ at 1130 UT to $24 \mathrm{~nm}$ at 1900 UT. The nucleation/Aitken mode particles continuously grew during this period. Rate of growth of the 9-26 nm diameter particles is calculated as $1.9 \mathrm{~nm} \mathrm{~h}^{-1}$ following the procedure of Kulmala et al (2004) in which the total particle number concentration in the size range $\left(D, D_{\max }\right)$, where $D$ is the diameter and $D_{\max }$ is the maximum size the critical clusters can reach, is divided by the time interval of the growth period. Losses due to both, coagulation and transport are neglected because the Antarctic site is relatively clean and has homogenous airmasses. Lower particle concentrations in clean environment of Antarctica will lower the efficiency of coagulation process. Furthermore, an additional transitory maximum occasionally appeared between 5 and $10 \mathrm{~nm}$ diameters when the aerosol size spectra were averaged for every 1-hour period, or the aerosol spectra obtained from the SMPS at every 10 minutes interval, were examined. For example, figure 8 shows four hourlyaveraged curves of aerosol particles on February 18 and the continuous growth of these nucleation mode particles to $20-30 \mathrm{~nm}$ diameter size. Particles in this mode grew to larger sizes and the new mode at 12-24 nm diameter resulted because of the growth of these nucleation mode particles. Our measurements on January 17, did not extend to sizes $<16 \mathrm{~nm}$ diameter. Our observations of large concentrations of intermediate ions during the high Sun period on February 18, 2005 support the formation and growth of nucleation particles by photochemical reactions or the transport of nucleation particles from other regions. Although, 
(a)

$\mathrm{dN} / \mathrm{dlog} \mathrm{D}(\mathrm{cm}-3)$

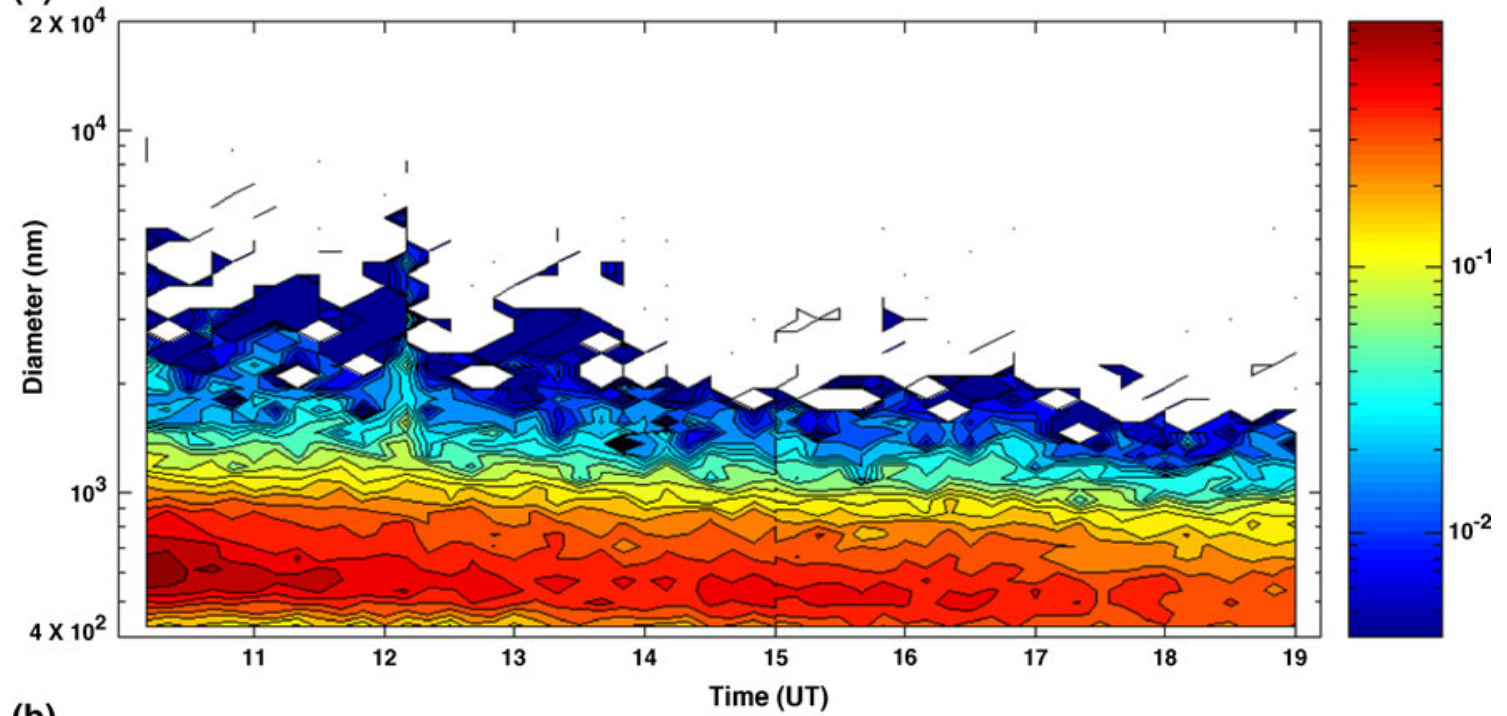

(b)

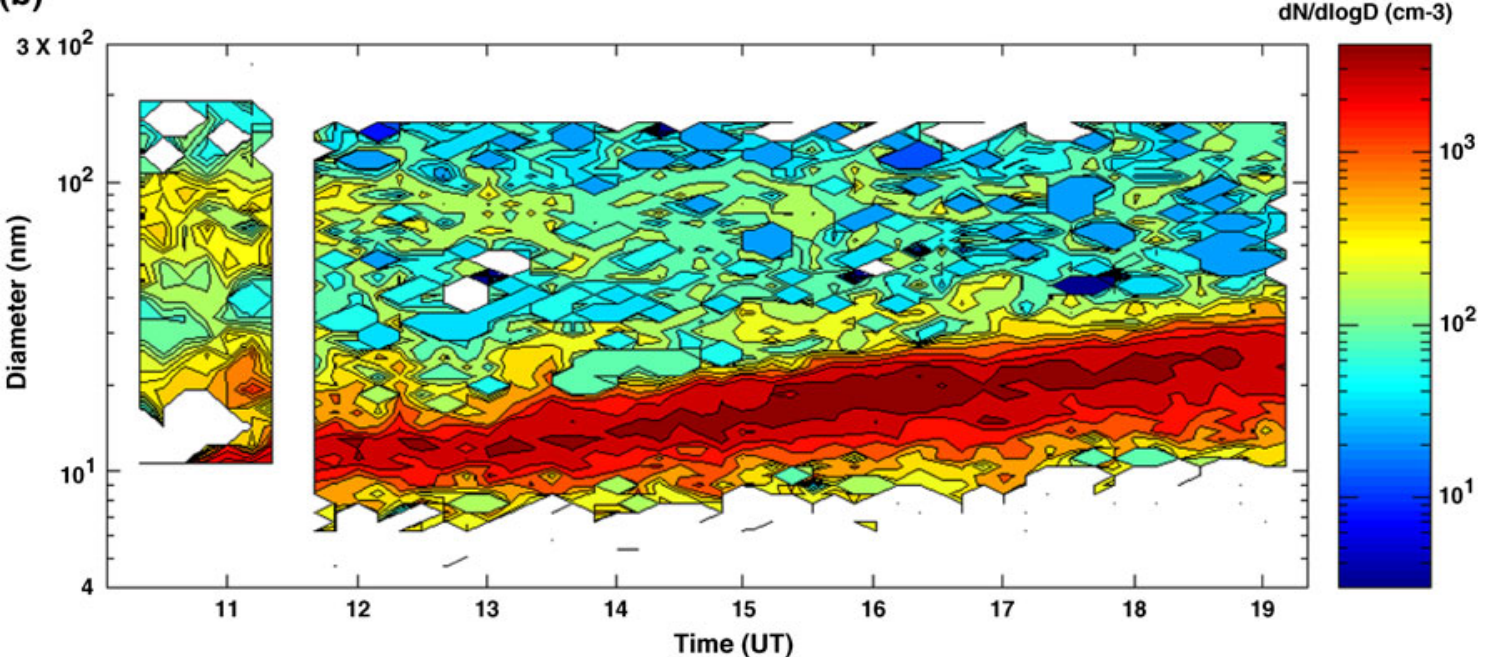

Figure 7. Time variations of the size distributions of particles on February 18, 2005. Size range (a) exhibits a maximum at 700-900 nm diameter and size range (b) exhibits two maxima at 60-100 nm and 12-24 nm diameters. Particles of 9-26 nm diameter grow at the rate of $1.9 \mathrm{~nm} \mathrm{~h}^{-1}$.

lower intensity of solar radiation available under cloudy conditions, may lead to lower rate of new particle formation, there are several observations that indicate new particle formation during the cloudy conditions and even at night-time without UV but under low condensation sinks (e.g., Wiedensohler et al 1997; Meters et al 2005; Lee et al 2008). Although, no specific mechanism has been identified so far for this night-time unconventional nucleation, Lee et al (2008) discuss some probable mechanisms in view of the past observations of such nucleation. Moreover, large particles in the size-range of $500-20,000 \mathrm{~nm}$ show a slow but steady decrease in size and concentration, most probably due to gravitational settling and vertical mixing of such particles with slow dynamical processes.

\section{Ion generation and ion-aerosol interactions}

In view of very small radioactivity in Antarctic soil at Maitri (Ramachandran and Balani 1995), cosmic rays are the main source for the small ion generation. These small ions soon get attached to the aerosol particles to form large ions. Mode diameters in common size ranges in size distribution of aerosol particles in lower panels of figures 6 and 7 are not much different from those illustrated in histograms of the size distribution of ions in figures 4 and 5. To illustrate this, the size distributions of both the aerosol particles measured with the SMPS and the positive/negative ions measured with the GICB on January 17 are plotted in figure 9. In the 16-107 nm diameter size range in figure 9, both 


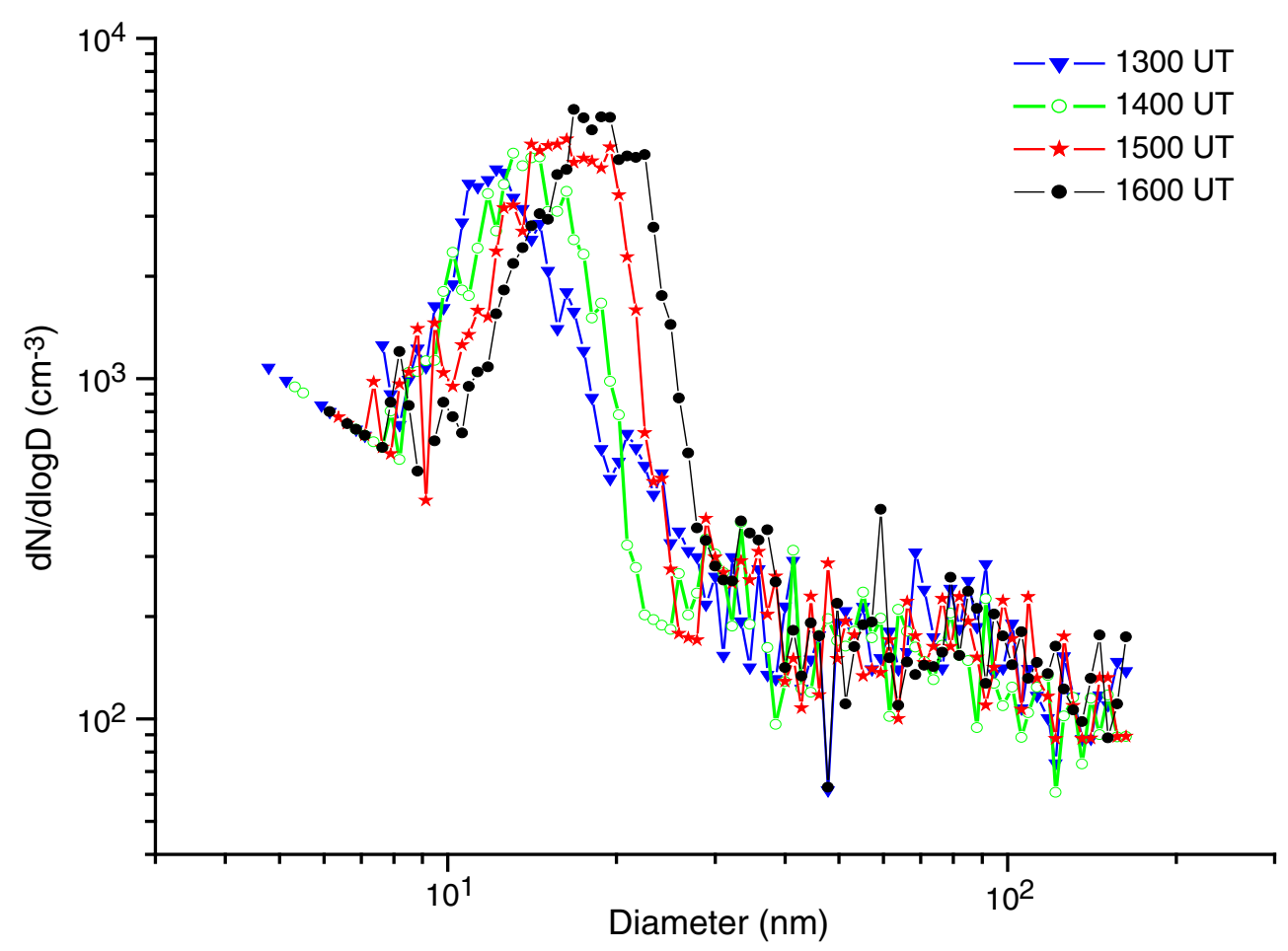

Figure 8. The hourly-averaged size distributions of (dN/dlogD) on February 18, 2005.

size distributions are bimodal or have a tendency to become so, as discussed below. Aerosol size distributions always show a peak in the range of 80 $120 \mathrm{~nm}$ diameter and a less prominent dynamical peak between 20 and $50 \mathrm{~nm}$ diameter in seven out of eight cases. The ion size distributions also indicate an increase in concentration beyond $80 \mathrm{~nm}$ diameter (see also from histograms in figure 4) in six out of eight cases and always a broad peak extending from 16-50 nm diameter. Increases in ion concentrations beyond $80 \mathrm{~nm}$ may be indirectly inferred to be associated with the occurrence of peaks in ion size distributions for ions exceeding $80 \mathrm{~nm}$ as suggested by histograms in figure 4. So, the agreement between the two curves is good considering the difference in averaging times of the two curves. Also shown in each panel of figure 9 are the total number of aerosol particles $(\mathrm{N})$ and ions $\left(\mathrm{N}_{+}\right.$ or $\mathrm{N}_{-}$) in the common size range of $16-107 \mathrm{~nm}$ diameter covered by both the SMPS and GICB. Ratio of $\mathrm{N}$ and $\mathrm{N}_{+}$or $\mathrm{N}_{-},\left(\mathrm{N} / \mathrm{N}_{+/-}\right)$, also shown in each panel, varies from 4.03 to 6.59 , and shows that only 15 to $25 \%$ of total number of aerosol particles in this size range are charged.

It is interesting to note that the ratio $\mathrm{N} / \mathrm{N}_{+/-}$ in all panels of figure 9 is always more than 1 when the particle and ion diameters are $\geq 30 \mathrm{~nm}$ and particle and ion concentrations are $\geq 100 \mathrm{~cm}^{-3}$ and becomes less than 1 when particle/ion diameters are $\leq 30 \mathrm{~nm}$ and particle ion concentrations are $\leq 100 \mathrm{~cm}^{-3}$ and this transition occurs when ion concentration is approximately maximum. Since $\mathrm{N} / \mathrm{N}_{+/-}<1$ is unphysical, we propose that part of the ion counter's current signal corresponding to $16-30 \mathrm{~nm}$ diameter ion concentration is due to the multiple charged particles collected in ion counter and thus the actual ion number concentration in this size-range may be smaller than the calculated value. These multiple charged particles may result because of the coagulation of charged particles. Consequently, the concentration of ions in this size-range, which falls in the light large ion category, calculated from the ion mobility spectra, will be an overestimate and must be corrected for the presence of multiple charged particles. It needs to be noted that for the growth of particles $\geq 30 \mathrm{~nm}$ in diameter, the coagulation process becomes significant. Theoretical solutions of ion-aerosol balance equations including the effects of ion-aerosol attachments and particle coagulation, also show that, for a given rate of ion production, fraction of multiple charged aerosol particles becomes significantly high when total aerosol particle concentration exceeds some critical value (Dhanorkar and Kamra 2001, 2003). Above this critical value of aerosol particle concentration, the concentration of singly charged aerosol particles decreases but that of multiple charged particles keeps increasing. For example, for a rate of ion generation of 10 ion pairs $\mathrm{cm}^{-3}$, the fraction of multiple charged particles exceeds $10 \%$ of the total particle concentration when total particle concentration is higher than 


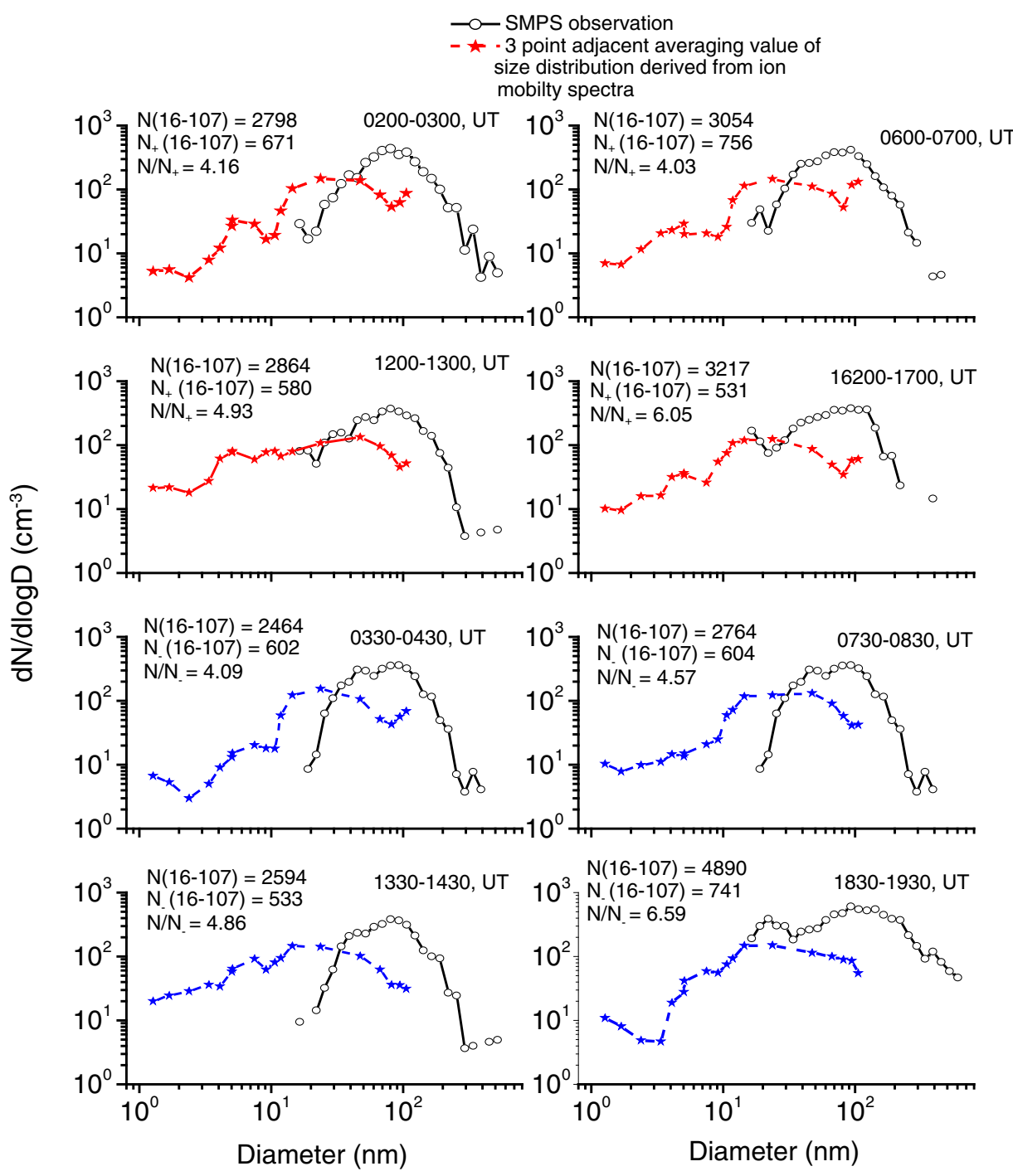

Figure 9. The size distributions of both the aerosol particles measured with SMPS and the positive/negative ions measured with the ion counter on January 17, 2005. Each panel also displays the total concentrations of aerosol particles (N), ions $\left(\mathrm{N}_{+/-}\right)$and the ratio $\left(\mathrm{N} / \mathrm{N}_{+/-}\right)$of the ions/particles in the size-range of 16-107 nm diameter.

$10^{3} \mathrm{~cm}^{-3}$. Such multiple charged particles appreciably contribute also to the electrical conductivity of the atmosphere (Dhanorkar and Kamra 2001). Such values of the rate of ion production and aerosol concentrations can be typically found at a coastal station in Antarctica. Therefore, in addition to multiple charged large ions of a few micron sizes, multiple charged ions in the size range of 16$30 \mathrm{~nm}$ also need to be considered in the ion-aerosol interaction studies.

Inspite of much different aerosol size-distributions on January 17 and February 18 (figure 10), the ion size distributions were nearly similar to each other on these two days. The main difference was due to the appearance of a dominating peak in nucleation mode in the aerosol size distributions as a result of the formation and growth of new particles on February 18. However, ion number concentrations in ion distribution in this size-range did not show any proportionately enhanced values corresponding to this peak. The peak between 80 and $120 \mathrm{~nm}$ corresponds to the large ions peak. The mode at $39 \mathrm{~nm}$ in aerosol size distribution, often dominated, specially after a burst event of nucleation particles, and sometimes enveloped the other mode at $85 \mathrm{~nm}$. Observations of Koponen et al (2003) at Aboa station, $130 \mathrm{~km}$ from the Antarctic coast, show that both marine/coastal and continental airmasses displayed bimodal aerosol size distributions.

To explain the generation of light large ions at Maitri, the mechanisms of snow crystal collisions (Vana et al 2008) or of depletion of particles (Hoppel et al 1990), need not be evoked. Moreover, our data does not support these mechanisms since light large ions were observed to be present even 


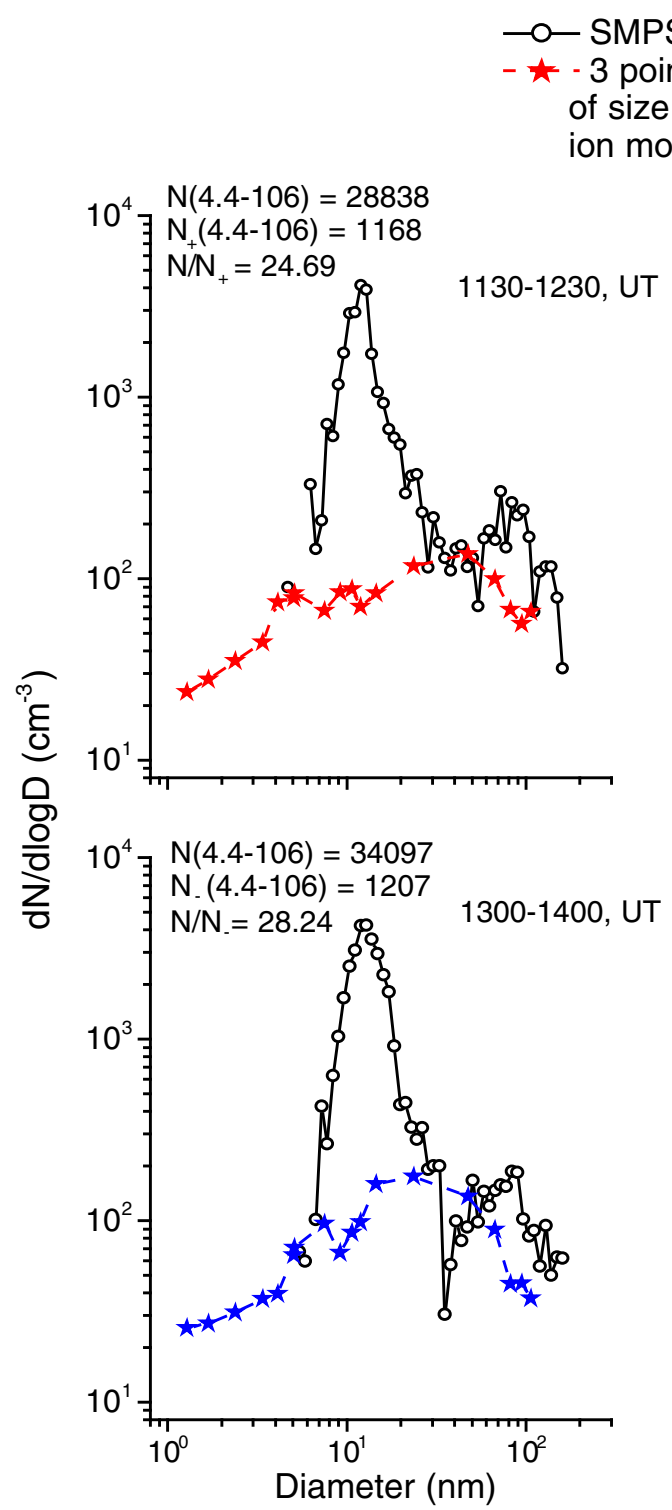

SMPS Observation

adjacent averaging value of size distribution derived from mobility spectra

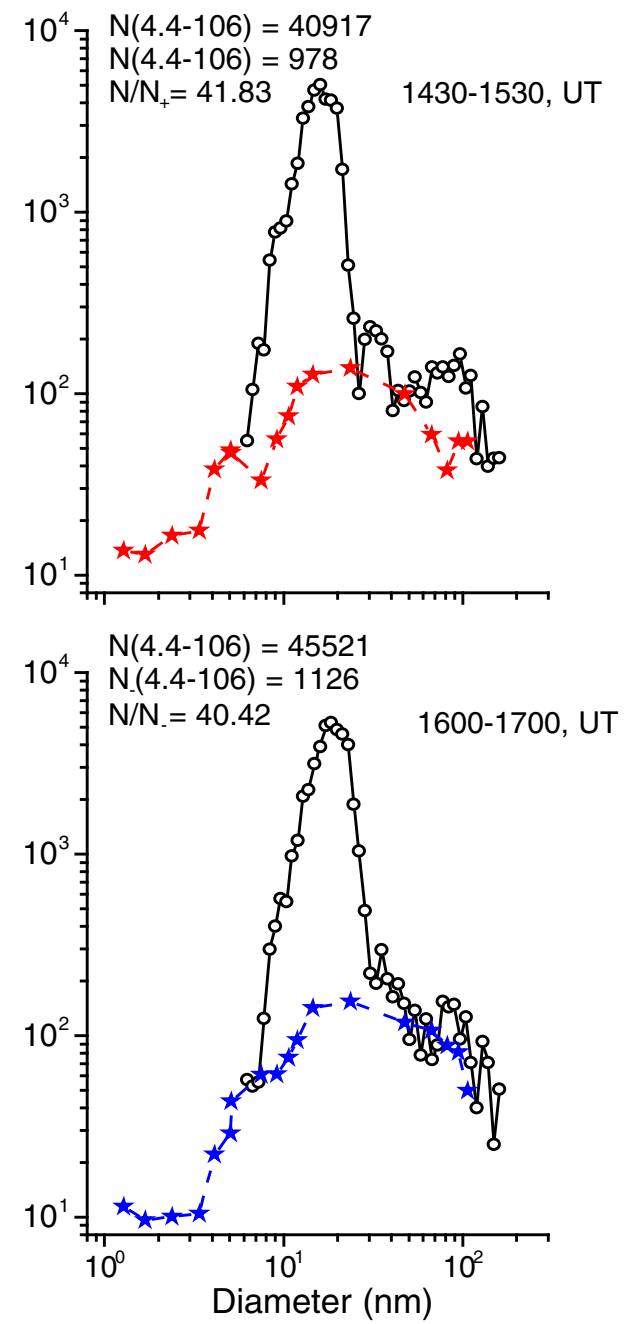

Figure 10. The size distributions of both the aerosol particles measured with SMPS and the positive/negative ions measured with the ion counter on February 18, 2005. Displays of $\mathrm{N}, \mathrm{N}_{+/-}$and $\mathrm{N} / \mathrm{N}_{+/-}$as in figure 7, but for the ions/particles in the size-range of 4.4-106 nm diameter.

when winds are low and/or particle concentration was large. Under these conditions, the abovementioned two mechanisms were not likely to operate. Attachment of small ions to Aitken particles with biomodal distributions and introduction of multiple charged ions may result in the formation of light and heavy large modes in the ion mobility spectra.

Our observations of higher concentrations of Aitken particles during the high Sun than in the low Sun periods support their generation by photochemical reactions during the high Sun periods. The low aerosol surface area provided by their low concentration in the clean Antarctic environment and the presence of high concentrations of sulphate and DMS at coastal stations in Antarctica support the generation of such ion/particles by photochemical processes during the high Sun periods.

\section{Discussion}

During the same expedition to Antarctica, Pant et al (2010) observed nucleation mode particles at Maitri when a cyclonic storm, revolving around the continent of Antarctica, was going away from Maitri. Our observations of the new particle formation on February 18 and not on January 17 can be explained on this basis and thus can be related to the difference in airmasses on these two days. The surface wind-flow patterns (figure 11) on these two days clearly show that on February 18, 2005, a cyclonic storm was departing away from Maitri and 

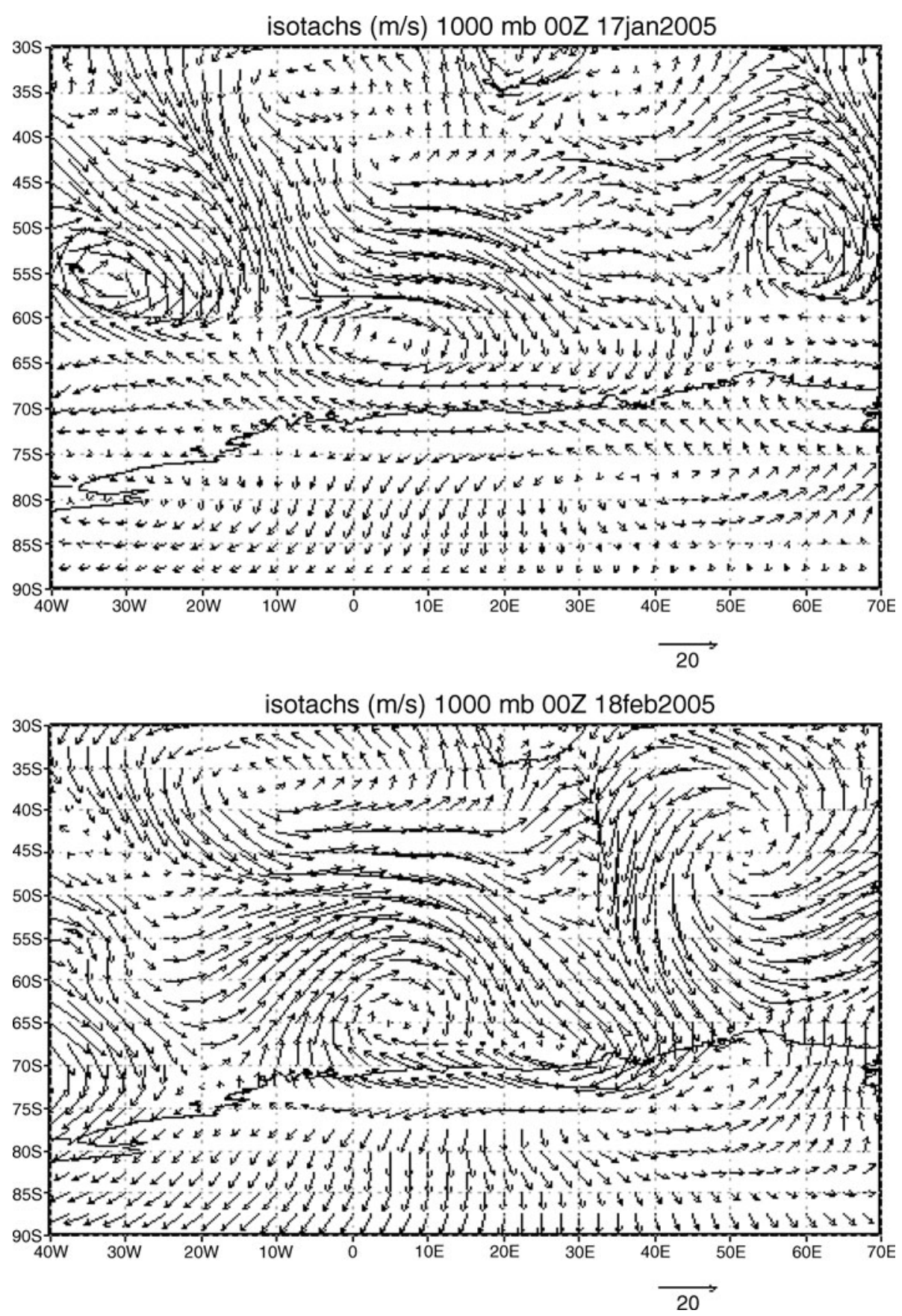

Figure 11. The surface wind flow patterns around Maitri from NCEP reanalysis data at 0000 UT each day on 17 January, 2005 (upper panel) and 18 February, 2005 (lower panel).

the airmass over Maitri was transported from lower latitudes. Further, the backward-trajectories in figure 3 show that this airmass descended from higher altitudes. The air flow over Maitri on this day was strongly influenced by the outflow of this cyclonic storm. Increasing tendency in atmospheric pressure throughout the day and the observations of strong winds in the morning hours and their subsequent decrease in the afternoon on February 18, observed at Maitri (figure 3), clearly indicate the passage of a low-pressure system going away from Maitri. The 5-day backward trajectories (figure 3) also show that the airmasses, before reaching Maitri on February 18, crossed the Antarctic coastline, joined the cyclonic circulation of the low pressure system over ocean and then re-curved again to re-enter the continent to arrive at Maitri from the eastward direction. Vertical trajectories on this day also show that the airmasses at 1200 UT and 1300 UT descended from altitudes of 2500-3000 m. In contrast, on January 17, the cyclonic system was far away 
from the coastline and, as shown in figure 11, the airmass over Maitri was not strongly influenced by its outflow. Meteorological records at Maitri also supported this (figure 2). Still, being in the subsidence region of the storm, the airmass over Maitri descended from the higher altitudes (figure 3 ). However, in sharp contrast to the case of February 18 , the airmass had no excursion over ocean before reaching over Maitri on January 17 (figure 3). So, although this airmass might have lowered some Aitken particles that were generated at higher altitudes and grew during their downward transport to the ground, but did not collect sufficient trace gases from the environment over ocean which are essential for the condensational growth of particles.

Higher concentrations of intermediate ions than that of cluster ions in our observations, can now be explained if the contribution of intermediate ions transported down from the higher altitudes and their direct induction into the lower atmosphere, during such periods of the cyclonic storm passage, are considered. Averaging of data over long periods of time, might average out the enhanced values during such periods.

Our observations of cluster ion concentrations were up to an order of magnitude smaller than those of Virkkula et al (2007) observed at Aboa, which is only $\sim 150 \mathrm{~km}$ away from Maitri. However, these values were of the same order as observed by Horrak et al (2003) at Takhuse and Komppula et al (2007) in the Baltic Sea region. The intermediate ion concentrations in our observations were comparable to those of other workers, mentioned above.

\section{Conclusions}

Our measurements of ion mobility spectra at Maitri always show two modes - one each for intermediate ions and light large ions, and indicate for additional one/two peaks in the mobility ranges of small/cluster ions and heavy large ions. Simultaneous observations of two Aitken modes in aerosol size distributions support the observation of two maxima observed for light and heavy large ions in the ion mobility spectra. Further, the formation of multiple charged ions by coagulation of charged particles may significantly contribute to the light large ion concentration. The small ions generated by cosmic rays and the nucleation mode particles, possibly generated by photochemical processes, grew by condensation of trace gases to cluster and intermediate ions and Aitken particles. Particles of diameter 9 to $26 \mathrm{~nm}$ have been observed to grow at the rate of $1.9 \mathrm{~nm} \mathrm{~h}^{-1}$ on February 18, 2005. Attachment of small ions to aerosol particles in two modes at 20-50 nm and 80-120 nm diameters, together with the introduction of multiple charged ions, have been proposed as the cause for the formation of light and heavy large ions.

Our measurements at Maitri clearly bring out the advantages of making measurements of atmospheric ion spectra over a large size range by using the technique of the differential measuring in GICB. For example, the growth of particles from the nucleation to Aitken mode, and the ion-aerosol interaction processes discussed in section 5, cannot be fully understood without the GICB measurements of particles of $<3 \mathrm{~nm}$ diameter. Moreover, such simultaneous measurements of ions and aerosol provide information about the charged fractions of aerosols which is of vital importance for the cloud micro-physical processes, aerosol stability, communication, etc.

It may be mentioned here that the results and conclusions drawn in this paper, are based on a meager data of only two days, viz., on January 17 and February 18, 2005, and as such should therefore, be taken as case studies. Results and the conclusions drawn in this case study are, therefore, valid for these two days. More data spanning over much longer periods, such as those of Virkkula et al (2007); Komppula et al (2007); Vartiainen et al (2007), are needed to be analysed before such conclusions are generalized.

\section{Acknowledgements}

Authors gratefully acknowledge the National Centre for Antarctic and Ocean Research (NCAOR) Goa, India for their participation in the 24th Indian Scientific Expedition to Antarctica (ISEA) and the India Meteorological Department for providing the metrological data. They thank Kirankumar Johare (JSO) for his technical help. Authors also acknowledge the NOAA Air Resources Laboratory (ARL) for the provision of the HYSPLIT transport and dispersion model and READY website (http://www.arl.nioaa.gov.ready.html) and NCEP reanalysis data provided by the NOAA/OAR/ ESRL PSD, Boulder, Colorado, USA, from their website (http://www.cdc.noaa.gov). One of the authors (AKK) acknowledges the support under the INSA Senior Scientist Programme. The authors thank the anonymous reviewers for their critical comments which helped in improving the scientific value of this paper.

\section{References}

Blackwood O 1920 The evidence of homogenous groups of larges ions; Phys. Rev. 16 85-101.

Bricard J 1949 L'equilibre ionique de la bassc atmosphere; J. Geophys. Res. 54 39-52. 
Bricard J 1962 La fixation de petits ions atmospheriques sur les aerosols ultra-fins; Geofis. Pura Appl. 51 237-242.

Dhanorkar S and Kamra A K 1991 Measurement of mobility spectrum and concentration of all atmospheric ions with a single apparatus; J. Geophys. Res. 96 18,67118,678 .

Dhanorkar S and Kamra A K 1993 Diurnal variations of the mobility spectrum of ions and size distribution of fine aerosols in the atmosphere; J. Geophys. Res. 98 2639-2650.

Dhanorkar S and Kamra A K 2001 Effect of coagulation on the particle charge distribution and air conductivity; J. Geophys. Res. 106 12,055-12,065.

Dhanorkar S and Kamra A K 2003 Effect of coagulation on the asymmetric charging of aerosols; Atmos. Res. 66 159-173.

Draxler R R and Rolph G D 2003 HYSPLIT (Hybrid SingleParticle Lagrangian Integrated Trajectory) Model access via NOAA ARL READY website (http://www.arl.noaa. gov/ready/hysplit4.html); NOAA Air Resources Laboratory, Silver Spring, MD.

Gagne S, Laakso L, Petaja T, Kerminen V-M and Kulmala M 2008 Analysis of one year of ion-DMPS data from the SMEAR II station. Finland; Tellus 60B 318-329.

Hirsikko A, Bergman T, Laakso L, Riipinen M Dal Maso, Horrak U and Kulmala M 2007 Identification and classification of the formation of intermediate ions measured in boreal forest; Atmos. Chem. Phys. 7 201-210.

Hoppel W A 1977 Ion aerosol attachment coefficients and the diffusional charging of aerosols; In: Electrical Processes in Atmospheres (eds) Dolezalek H and Reiter R (Darmstadt: Dr. Dietrich Steinkopff Verlag) 60-69.

Hoppel W A, Fitzgerald J W, Frick G M, Larson R E and Mack E J 1990 Aerosol size distribution and optical properties found in marine boundary layer over the Atlantic Ocean; J. Geophys. Res. 95 3659-3686.

Horrak U, Iher H, Luts A, Salm J and Tammet H 1994 Mobility spectrum of air ions at Takhuse observatory; J. Geophys. Res. 99 10,697-10,700.

Horrak U, Mirme A, Salm J, Tamm E and Tammet H 1998 Air ion measurements as a source of information about atmospheric aerosols; Atmos. Res. 46 233-242.

Horrak U, Salm J and Tammet H 2000 Statistical characteristic of air ion mobility spectra at Tahkuse Observatory: Classification of air ion; J. Geophys. Res. 105 9291-9302.

Horrak U, Salm J and Tammet H 2003 Diurnal variation in the concentration of air ions of different mobility classes in a rural area; J. Geophys. Res. 108 4653, doi: 10.1029/2002JD003240.

Horrak U, Aalto P P, Salm J, Komsaare K, Tammet H, Makel J M, Laakso L and Kulmala M 2008 Variation and balance of positive air ion concentrations in a boreal forest; Atmos. Chem. Phys. 8 655-675.

Israel H 1970 Atmospheric Electricity, Vol. 1. Israel Program for Scientific Translations, Jerusalem, 317 pp.

Khlystov A, Stanier C and Pandis S N 2004 An algorithm for combining electrical mobility and aerodynamic size distributions data when measuring ambient aerosol; Aerosol Sci. Tech. 38(S1) 229-238.

Kirkby J 2007 Cosmic rays and climate; Surv. Geophys. 28 333-375, doi: 10.1007/s10712-008-9030-6.

Kojima H 1984 Relation between intermediate ions and meteorological factor; Res. Let. Atmos. Electr. 4 49-53.

Komppula M, Vana M, Kerminen V-M, Lihavainen H, Viisanen Y, Hõrrak U, Komsaare K, Tamm E, Hirsikko A, Laakso L and Kulmala M 2007 Size distributions of atmospheric ions in the Baltic Sea region; Boreal Env. Res. 12 323-336.
Komsaare K, Hõrrak U, Tammet H, Siingh D, Vana M, Hirsikko A and Kulmala M 2007 Classification of intermediate air ion formation events at Tahkuse Observatory, Estonia; Proceeding of 13th International Conference on Atmospheric Electricity, Beijing, China, 13-17 August, 2007.

Koponen I K, Virkkula A, Hillamo R, Kerminen V-M and Kulmala M 2003 Number size distributions and concentrations of the continental summer aerosols in Queen Maud Land, Antarctic; J. Geophys. Res. 108(D18) 4587, doi: 10.1029/2003JD003614.

Kulmala M, Vehkamaki H, Petäjä T, Maso M Dal, Lauri A, Kerminen V-M, Birmili W and McMurry P 2004 Formation and growth rates of ultrafine atmospheric particles: A review of observations; J. Aerosol Sci. 35(2) 143-176.

Kulmala M, Riipinen I, Sipilä M, Manninen H E, Petäjä T, Junninen Hi, Maso M Dal, Mordas G, Mirme A, Vana M, Hirsikko A, Laakso L, Harrison Roy M, Hanson I, Leung C, Lehtinen K E J and Kerminen Veli-Matti 2007 Toward direct measurements of atmospheric nucleation; Science 318 89-91.

Lee S-H, Young L-H, Benson D R, Suni T, Kulmala M, Junninen H, Campos T L, Rogers D C and Jensen J 2008 Observations of nighttime new particle formation in the troposphere; J. Geophys. Res. 113 D10210, doi: 10.1029/2007JD009351.

Meters S, Galgon D, Schwirn K, Nowak A, Lehmann K, Massling A, Wiedensohler A and Wieprecht W 2005 Evolutions of particle concentration and size distribution observed upwind, inside and downside hill cap clouds at connected flow condition during FEBUKO; Atmos. Environ. 39 4233-4245.

Misaki M 1961 A method of measuring the ion spectrum; Papers Meteorol. Geophys. Tokyo 1 313-318.

Misaki M 1964 Mobility spectrums of large ions in the New Mexico semi-desert; J. Geophys. Res. 69 3309-3318.

Misaki M, Ohtagaki M and Kanazawa I 1972 Mobility spectrometry of the atmospheric ions in relations to atmospheric pollution; Pure Appl. Geophys. 100 133-145.

Nagato K and Ogawa T 1998 Evaluation of tropospheric ions observed by an ions mobility spectrometer with a drift tube; J. Geophys. Res. 103 13,917-13,925.

Ondracek J, Zdimal V, Smolik J and Lazaridis M 2009 A merging algorithm for aerosol size distribution from multiple instruments; Water Air and Soil Pollution 199 219-233, doi: 10.1007/s11270-008-9873-y.

Pant V, Despande C G and Kamra A K 2008 On the aerosol number concentration-wind speed relationship during a severe cyclonic storm over South Indian Ocean; J. Geophys. Res. 113 D02206, doi: 10.1029/2006JD008035.

Pant V, Siingh D and Kamra A K 2010 Concentrations and size distributions of aerosol particles at Maitri during the passage of cyclonic storms revolving around the continent of Antarctica; J. Geophys. Res. 115 D17202, doi: 10.1029/2009JD013481.

Pant V, Siingh D and Kamra A K 2011 Size distribution of atmospheric aerosols at Maitri, Antarctica; Atmos. Environ. 45 5138-5149, doi: 10.1016/j.atmosenv.2011.06.028.

Park J, Sakurai H, Vollmers K and Mcmurry P H 2004 Aerosol size distribution measured at South Pole during ISCAT; Atmos. Environ. 38 5493-5500.

Peters T M, Chein H M, Lundgren D A and Keady P B 1993 Comparison and combination of aerosol size distributions measured with a low pressure impactor, differential mobility particle sizer, electrical aerosol analyzer, and aerodynamic particle sizer; Aerosol Sci. Technol. 19 396-405. 
Raes F, Van Dingenen R, Vignati E, Wilson J, Putaud J P, Seinfeld J H J and Adams P 2000 Formation and cycling of aerosol in the global troposphere; Atmos. Environ. 34 4215-4240.

Ramachandran T V and Balani M C 1995 Report on the participation by the Bhabha Atomic Research Centre in the Tenth Indian Expedition to Antarctica, Scientific Report on Tenth Indian Expedition to Antarctica; Tech. Publ., Dept. of Ocean Development, Govt. of India, New Delhi, India, 8 159-180.

Rycroft M J, Israelsson S and Price C 2000 The global atmospheric electric circuit, solar activity and climate change; J. Atmos. Solar Terr. Phys. 62 1563-1576.

Siingh D and Singh R P 2010 The role of cosmic rays on the Earth's atmosphere; Pramana - J. Phys. 74 153-168.

Siingh D, Pawar S D, Gopalakrishnan V and Kamra A K 2005a Measurements of ion concentrations and conductivity over the Arabian Sea during the ARMEX; J. Geophys. Res. 110 D18207, doi: 10.1029/2005JD005765.

Siingh D, Singh R P, Kamra A K, Gupta P N, Singh R, Gopalakrishnan V and Singh A K 2005b Review of electromagnetic coupling between the Earth's atmosphere and space environment; J. Atmos. Solar Terr. Phys. 67 $637-658$.

Siingh D, Pant V and Kamra A K 2007a Measurements of positive ions and air-Earth current density at Maitri, Antarctica; J. Geophys. Res. 112 D13212, doi: 10.1029/2006JD008101.

Siingh D, Gopalakrishnan V, Singh R P, Kamra A K, Singh S, Pant V, Singh R and Singh A K 2007b The atmospheric global electric circuit: An overview; Atmos. Res. 84 91-110.

Siingh D, Singh A K, Patel R P, Singh R P, Venadhari B and Mukherjee M 2008 Thunderstorm, lightning, sprites and magnetospheric whistler mode radio wave; Surv. Geophys. 29 499-551, doi: 10.1007/s10712-008-9053-z.

Siingh D, Singh R P, Singh A K, Kulkarni M N, Gautam A S and Singh Abhay K 2011 Solar activity, lightning and climate; Surv. Geophys., doi: 10.1007/s10712-011-9127-1, published online 21 May 2011.

Singh D K, Singh R P and Kamra A K 2004 The electrical environment of the Earth's atmosphere: A review; Space Sci. Rev. 113 375-408.

Singh A K, Siingh D and Singh R P 2011 Impact of galactic cosmic rays on the Earth's atmosphere and human health; Atmos. Environ. 45 3805-3815, doi: 10.1016/j.atmosenv.2011.04.027.

Tammet H 1992 Comparison of model distributions of aerosol particles sizes; Acta et. Comm. Uni. Tartuensis $947136-149$.

Tammet H 1995 Size and mobility distribution of nanometer particles, cluster and ions; J. Aerosol Sci. 26 459-475.

Tinsley B A 2000 Influence of solar wind on the global electric circuit, and inferred effects on the cloud microphysics, temperature, and dynamics in troposphere; Space Sci. Rev. 94 231-258.

Tinsley B A 2008 The global atmospheric electric circuit and its effects on cloud microphysics; Rep. Prog. Phys. 71(066801):31, doi: 10.1088/0034-4885/71/6/066801.

Vana M, Kulmala M, Maso M Dal, Horrak U and Tamm E 2004 Comparative study of nucleation mode aerosol particles and intermediate ions formation events at three sites; J. Geophys. Res. 109 D17201, doi: 1029/2003JD004413.

Vana M, Ehn M, Petaja T, Vuollekoski H, Aalto P, de Leeuw G, Ceburnis D, O'Dowd Colin D and Kulmala M 2008 Characteristic features of air ions at Mace Head on the west coast of Ireland; Atmos. Res. 90 278-286.

Vartiainen E, Kulmala M, Ehn M, Hirsikko A, Junninen H, Petäjä T, Sogacheva L, Kuokka S, Hillamo R, Skorokhod A, Belikov I, Elansky N and Kerminen V-M 2007 Ion and particle number concentrations and size distributions along the Trans-Siberian railroad; Boreal Env. Res. 12 375-396.

Virkkula A, Hirsikko A, Vana M, Aalto Pasi P, Hillamo R and Kulmala M 2007 Charged particle size distribution and analysis of particle formation events at Finnish Antarctic research station, Aboa; Borel Environ. Res. 12 397-408.

Wiedensohler A et al 1997 Night-time formation and occurrence of new particles associated with orographic clouds; Atmos. Environ. 31 2545-2559.

Whipple E C 1960 An improved technique for obtaining ion mobility distributions; J. Geophys. Res. 65 36793684 .

Yu F 2010 Ion-mediated nucleation in the atmosphere: Key controlling parameters, implications, and look-up table; $J$. Geophys. Res. 115 D03206, doi: 10.1029/2009JD012630.

Williams E R 2009 The global electrical circuit: A review; Atmos. Res. 91 140-152, doi: 10.1016/j.atmosres.2008.05. 018. 